\begin{abstract}
Title of thesis: $\quad$ TRANSFORMING VACANT LOTS: INVESTIGATING AN ALTERNATIVE APPROACH TO REDUCING FEAR OF CRIME
\end{abstract}

Alaina M. De Biasi, Master of Arts, 2015

Thesis directed by: Professor Jean McGloin

Department of Criminology and Criminal Justice

Vacant lots deserve criminological attention insofar as their disorderly conditions create opportunities for a host of negative outcomes including "fear of crime." The present study considers whether incorporating fundamental standards of Crime Prevention through Environmental Design (CPTED) into traditional urban greening practices of vacant lots provides added value with regard to fear of crime above and beyond the traditional endeavor. This study conducted an experiment $(\mathrm{N}=523)$ from a sample of undergraduate students. Research participants were asked to report their level of fear of crime in regards to one of three randomly assigned computer-adjusted images: 1) A disorderly lot; 2) A traditional greened lot; and 3) A CPTED lot. This study found that on average participants who viewed a CPTED lot had lower levels of fear of crime than all other participants. This study discusses the implications of this finding for future research. 


\title{
TRANSFORMING VACANT LOTS: INVESTIGATING AN ALTERNATIVE APPROACH TO REDUCING FEAR OF CRIME
}

\author{
By \\ Alaina M. De Biasi \\ Thesis submitted to the Faculty of the Graduate School of the University of Maryland, \\ College Park in partial fulfillment of the requirements for \\ the degree of Master of Arts \\ 2015
}

Advisory Committee:

Professor Jean McGloin, Chair Assistant Professor Lauren Porter Associate Professor Min Xie 
(C) Copyright by Alaina M. De Biasi 2015 


\section{Acknowledgements}

I would like to thank Dr. Jean McGloin for her support and guidance and for always giving me the best advice. I would also like to thank Dr. Min Xie and Dr. Lauren Porter for their guidance and helpful critiques throughout this process. In addition, my cohort has been a constant source of support. The individuals of my cohort have played an instrumental role in my graduate school experience. I am thankful for the opportunity to have studied and grown as a researcher alongside these amazing individuals. Finally, I would like to thank my friends, family members and, in particular, James Podges for their unwavering love and support. 


\section{Table of Contents}

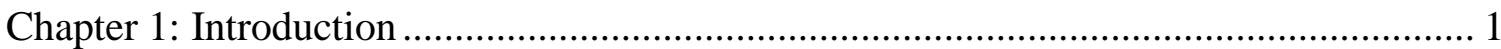

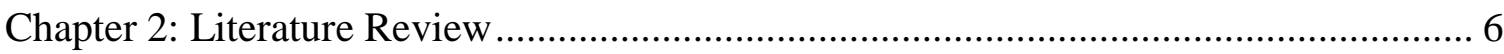

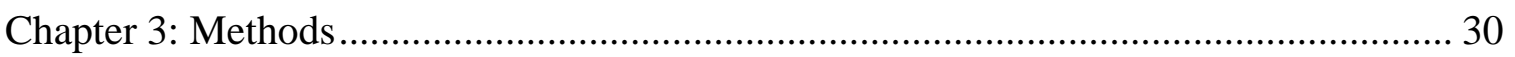

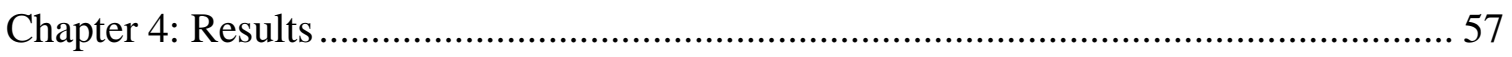

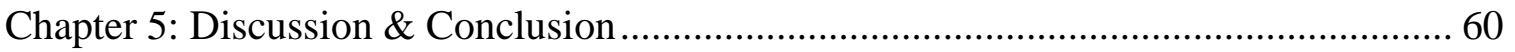

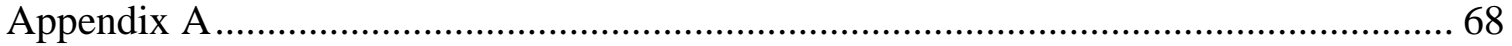

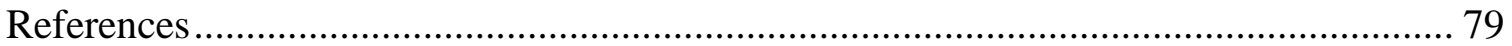




\section{List of Tables}

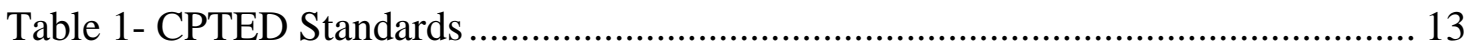

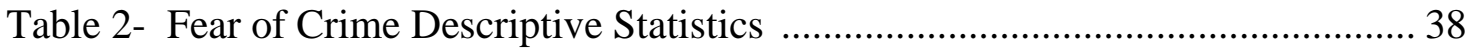

Table 3- Polychoric Correlation Matrix ................................................................... 43

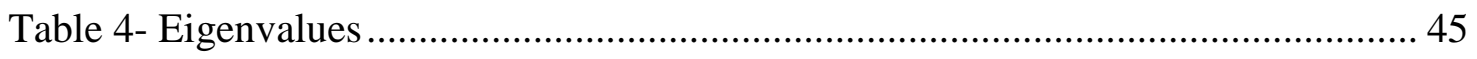

Table 5- Fear of Crime Index Descriptive Statistics ............................................... 48

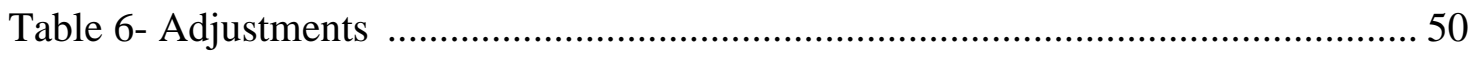

Table 7- Lumpkin's Abbreviated Locus of Control Scale ........................................... 54

Table 8- Indivdual-level Charcteristics Descriptive Statistics ..................................... 55

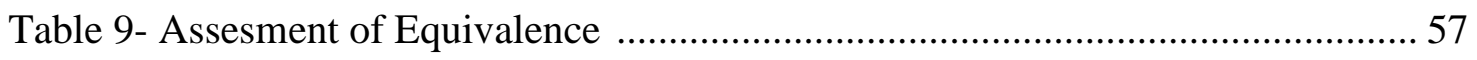

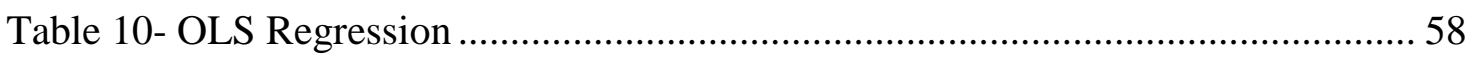

Table 11- OLS Regression with No Controls .......................................................... 93 


\section{List of Figures}

Figure 1 - Orignal Image of the Vacant Lots...................................................... 69

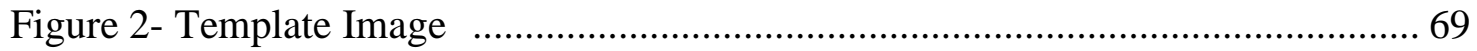

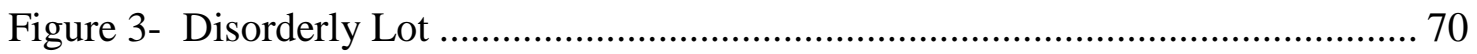

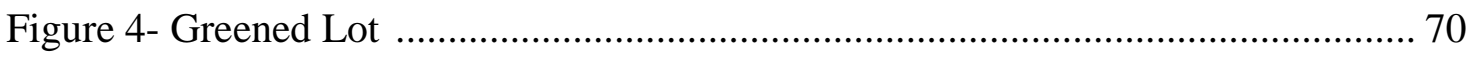

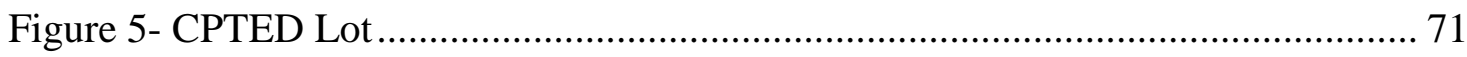

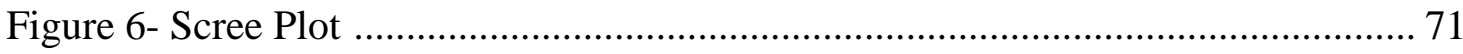




\section{Chapter 1: Introduction}

Vacant lots, defined as unkempt parcels of land with no buildings on them, are common features of city landscapes in the United States (U.S.) (Bowman \& Pagano, 2000; Burkholder, 2012; United States Environmental Protection Agency, 2013). In fact, on average $15 \%$ of a city's land in the U.S. is vacant (Bowman \& Pagano, 2000). ${ }^{1}$ Within cities, vacant lots are typically not only dominant features within their inner cores, but also in surrounding neighborhoods. For example, in some neighborhoods in Detroit, Michigan, such as Westwood Park, vacant lots comprise a greater proportion of land area than they do in the inner-city (Data Drive Detroit, 2015).

Vacant lots deserve criminological attention; their disorderly conditions create opportunities for a host of negative outcomes including "fear of crime" (Spelman, 1993; Wilson \& Kelling, 1982). Fear of crime has been demonstrated to negatively influence an individual's social, mental and physical health as well as, on a larger scale, the vitality of his or her community (Green, Gilbertson \& Grimsley, 2002; Morrall, Marshall, Pattison \& Macdonald, 2010; Ross \& Mirowsky, 2001; Wilson \& Kelling, 1982). In light of the detrimental outcomes associated with vacant lots as well as their prevalence in the U.S, understanding the connection between vacant lots and fear of crime is an important endeavor (Bowman \& Pagano, 2000). Research on this connection must develop more comprehensive methods to manage the disorderly conditions of vacant lots and to capitalize on the opportunity to reduce fear of crime.

\footnotetext{
${ }^{1}$ In order to minimize definitional disparities, Pagano and Bowman (2000) defined vacant land as including "publicly-owned and privately-owned unused or abandoned land or land that once had structures on it, but also the land that supports structures that have been abandoned, derelict, boarded up, partially destroyed, or razed" (p. 2). Although this figure does not solely focus on vacant lots, as defined by this study, it is able to provide a rudimentary understanding of their prevalence in U.S. cities.
} 
A common method city officials in Baltimore, New York City, Philadelphia and Detroit use to manage vacant lots in the inner-city as well as in surrounding neighborhoods is to transform them into green space, called "urban greening" (Baltimore Greenspace, 2013; Greening of Detroit, 2014; Pennsylvania Horticultural Society, 2014; Urban Green Council, 2014). The primary objective of urban greening is to improve the conditions of vacant lots by taking them from disorderly to orderly, which should then promote quality of life. To achieve this objective, urban greening efforts across the country commonly rely on a set of traditional (or standard) techniques referred to as “traditional urban greening practices." These traditional practices include planting grass and low-maintenance plants (e.g., trees) as well as focus on efforts to maintain the environment referred to as maintenance. Maintenance efforts involve removing debris and overgrowth, as well as other forms of physical disorder. Physical disorder includes environmental features that reflect neighborhood dilapidation such as graffiti, trash and other debris (Skogan, 1990). It is viewed as an environmental cue signaling unsafe places (Doran \& Lees, 2005; Hanyu, 1993), which in turn can increase fear of crime (Cinar \& Cubukcu, 2012; Fisher \& Nasar, 1992; Nasar \& Jones, 1997; Warr, 1990). Despite urban greening's attention to maintenance, thus far, no one has examined whether urban greening fully capitalizes on the opportunity to reduce fear of crime.

Urban greening's ability to transform disorderly environments through its focus on maintenance fits nicely within the framework of Crime Prevention though Environmental Design (CPTED), which aims to reduce crime and fear of crime (Pain, 2000; Perkins, Wandersman, Rich, \& Taylor, 1993; Schneider \& Kitchen, 2007). CPTED attempts to achieve these reductions through the implementation of environmental design 
standards while maintaining the underlying goal, like that of urban greening, of improving the quality of life of residents (Crowe, 1991; Perkins, Wandersman, Rich \& Taylor, 1993; Schneider \& Kitchen, 2007).

Unlike traditional urban greening practices, CPTED provides instruction on how to simultaneously enforce numerous design standards in addition to efforts to maintain the environment. These include the four most dominant CPTED standards: territoriality, surveillance, access control and maintenance. Due to their complementary nature, these design standards are more commonly implemented together as a package than in isolation of one another (Bureau of Justice Assistance, 2013). In fact, the complementary nature of these design standards makes it extremely difficult to untangle the ability of each standard to impact crime and fear of crime (Schneider \& Kitchen, 2002).

In addition, these standards are able to collectively influence an individual's perception of the environment which helps inform his or her level of fear of crime. Consequently, it is reasonable to believe that the collective enforcement of these design standards is able to affect an individual's level of fear of crime beyond that which could be achieved by the enforcement of one design standard alone. Although urban greening fits nicely within the framework of CPTED, it has yet to explicitly incorporate CPTED standards into traditional urban greening practices.

Incorporating CPTED standards into traditional urban greening practices is a worthwhile and relatively low-cost alteration to investigate. CPTED has the ability to transform vacant lots beyond the rudimentary maintenance efforts that are the focus of traditional urban greening practices. For example, urban greening practices have the tendency to create unstructured spaces that are not formally organized. Unstructured 
spaces may include, for instance, trees that are planted too closely together which create hiding places for offenders and impair individuals from quickly and easily escaping the advances of a potential offender. Such qualities may lead individuals to perceive themselves to be vulnerable to victimization. This perception ultimately mitigates urban greenings' ability to reduce fear of crime beyond that which is achieved through its focus on maintenance alone. CPTED, when fully incorporated into the greening process as a package, is expected to result in greater reductions of fear of crime by ensuring that space is not only maintained but also actively upholds additional design standards which collectively work together to guard against these, and other, qualities of unstructured spaces. By not collectively enforcing CPTED standards, it is likely that many cities in the U.S. are failing to capitalize on the opportunity to reduce fear of crime within communities in their conversion of vacant lots.

The present study will provide some preliminary commentary on whether greening incorporating CPTED standards into traditional urban greening practices might pay important and substantive dividends above and beyond traditional practices. To explore this uncultivated research area, this study will randomly assign subjects to one of three conditions. Participants will either receive an image of a disorderly lot (i.e., a vacant lot that is left in a disorderly state) a greened lot (i.e., a vacant lot that is greened according to the traditional practices previously mentioned) or a CPTED lot (i.e., a vacant lot that incorporates CPTED standards into the greening process). Using these images, this study will test the assumption that incorporating CPTED standards into traditional urban greening practices of vacant lots may provide added value with regard to fear of crime above and beyond the traditional endeavor. CPTED standards will be evaluated as 
a package rather than in isolation of one another. In the end, this study will provide an assessment on whether incorporating CPTED standards into the traditional urban greening practices described is a worthwhile effort to pursue in regards to achieving greater reductions of fear of crime. 
Chapter 2: Literature Review

Crime Prevention through Environmental Design (CPTED): General Background

CPTED uses a framework of environmental design standards with the goals of achieving a reduction in the incidence and fear of crime as well as an improvement in residents' quality of life (Crowe, 2000). In particular, CPTED relies on its ability to influence individuals' perceptions of the environment which are facilitated by the enforcement of its environmental design standards: territorially, surveillance, access control and maintenance. This study discusses these design standards, which represent the most dominant standards in CPTED literature, in detail in a later section. These environmental design standards work together to influence offenders' and non-offenders' (i.e., potential victims') perceptions of the environment differently. From an offender standpoint, these perceptions affect decisions to commit criminal acts. Alternatively, from a non-offender's or potential victim's standpoint, these perceptions affect fear of crime. The present section provides an overview of CPTED's historical development which highlights the mechanisms and environmental conditions (or cues) that influence criminal behavior and the formulation of CPTED standards. Lastly, this section begins building a rudimentary foundation to explore the relationship between the environment and fear of crime which is the focus of a later section and of this study.

CPTED was first introduced in Jeffery's (1971) publication of Crime Prevention through Environmental Design. This work was largely conceptual in nature. In it, Jeffery (1971) emphasized the role of the physical and social environment to produce positive (pleasurable) and negative (painful) experiences for offenders, a concept borrowed from Skinner's (1938) stimulus-response model. Under Skinner's (1938) perspective, 
offenders make choices based on their expectations of the positive and negative outcomes that could result from their decisions. Following this logic, Jeffery (1971) believed that it was possible to alter the environment to enhance the likelihood of conforming behavior while simultaneously mitigating criminal behavior. In particular, he advocated altering the physical environment as a means to decrease the positive expectations associated with decisions to offend and in doing so deter criminal behavior. In this way, Jeffery's (1971) work mirrored earlier analyses conducted by Jane Jacobs (1960), Elizabeth Wood (1961) and Scholomo Angel (1968) which suggested that alterations to certain physical design features of urban environments could deter potential offenders from committing crime. Later, Jeffery (1977) emphasized that the environment never influenced behavior directly. Rather, environmental cues trigger individuals' to formulate perceptions of their surroundings that are used in cognitive processes that influence behavior. For example, an environmental cue may signal to offenders that criminal acts will likely go undetected and unpunished. In this circumstance, offenders' positive expectations of their decisions to offend (e.g., monetary reward) would likely outweigh their expectations of any negative outcomes (e.g., punishment). Therefore, for offenders, this perception would likely motivate criminal behavior. Unfortunately, Jeffery $(1971,1977)$ does not elaborate on the underlying mechanism, fear of crime, which motivates the behaviors of nonoffenders. Other scholars, such as Newman (1972), fill this void.

Taking Jeffery's (1971) concept, Newman (1972) was one of the first scholars to discuss CPTED in practical terms. Unlike Jeffery (1971) who focused primarily on developing a conceptual backdrop for CPTED, Newman (1972) elaborated on CPTED by providing actual standards for what the physical environment should resemble in order to 
reduce not only crime but fear of crime and to promote quality of life. Similar to Jeffery (1971) and his predecessors, Newman (1972) argued that it was possible to design physical environments to decrease opportunities for crime as well as fear of crime by affecting the behavior of offenders and non-offenders. In particular, he suggested the following design standards were crucial and critical to this objective: territoriality, surveillance, image and milieu (Newman, 1972). Newman (1972) believed that a good design encourages residents to defend their communities and, in doing so, creates safer areas by signaling to offenders that criminal acts will not go undetected or unpunished. To this end, he advocated applying these standards in the creation of physical layouts of residential areas. For example, Newman (1972) emphasized the importance of design layouts that allowed residents to be able to regularly and effortlessly observe their surroundings. This ability deters crime and decreases fear of crime by allowing residents the opportunity to quickly and easily identify offenders which in turn increases offenders' risk of detection and likelihood of punishment while allowing non-offenders the security and comfort of avoiding unanticipated attacks.

Since the presentation of Newman's (1972) standards, several other scholars have helped shape the construction of CPTED standards. The contributions of these scholars have resulted in the development of arguably the four most dominant environmental design standards: territoriality, surveillance, access control and maintenance. Appleton's (1975) prospect-refuge theory and Wilson and Kelling's (1982) broken windows thesis are among the most significant contributions of these scholars. These contributions expand on Newman's (1972) assessment of CPTED by further describing certain 
physical conditions of the environment (i.e., environmental cues) that influence not only criminal behavior but also fear of crime.

In prospect-refuge theory, Appleton (1975) describes environments that facilitate feelings of safety and in doing so reduce fear of crime and the likelihood of criminal behavior. These environments include the following: 1) Environments that allow potential victims to have a clear view of their surroundings (prospect); 2) Environments that lack places for offenders to hide (refuge); and 3) Environments that allow opportunities for potential victims to easily and quickly escape the advances of an offender. However, in broken windows thesis, Wilson and Kelling (1982) describe an element that mitigates the effects of these environments. This element is physical disorder: environmental features that reflect neighborhood dilapidation such as graffiti, trash and other debris (Skogan, 1990). Physical disorder impairs prospect, provides refuge for offenders and mitigates the ability of individuals to quickly and easily escape the advances of potential offenders. In particular, physical disorder provides concealment for the perpetration of physical and sexual assaults and is also useful in providing opportunities for other attacks where surprising an unsuspecting victim benefits the attacker, such as in the case of robbery.

In addition, perceptions of physical disorder are a pivotal part of the broken windows process, a debilitating cycle that facilitates crime, fear of crime and the spread of disorder (Wilson \& Kelling, 1982). Physical disorder is more likely to be perceived (or recognized) in places where it is most prevalent, such as in vacant lots. Once perceived, physical disorder helps promote the belief that a community is free from the constraints of social control and that criminal acts will go unpunished. This belief 
facilitates increases in residents' fear of crime and the spread of physical disorder as well as encourages the proliferation of crime and unwanted public behaviors that are threatening but may or may not be unlawful (Keizer, Lindenberg, \& Steg, 2008; Wilson \& Kelling, 1982). Included among these behaviors is harassment, defined as unwelcome verbal and nonverbal behavior that occurs in public by a stranger or group of strangers. A bystander is more likely to become the victim of harassment in areas with high levels of physical disorder because in such places physical disorder is more likely to be perceived by offenders and non-offenders alike as a breakdown of the regulation, both formally and informally, of individual and group behavior. In essence, in areas with high levels of physical disorder, such as in and around vacant lots, there are less social inhibitions to discourage unwanted behaviors like harassment. Contrastingly, the beliefs that a community is free from the constraints of social control and that criminal acts will go unpunished are not likely to be enforced in places that have little physical disorder. Rather, such places foster the perception that they are under the surveillance and protection of the community and that unwanted behaviors will be detected and offenders punished. These perceptions help decrease residents' fear of crime, stifle the spread of physical disorder and strengthen the barriers against crime as well as unwanted public behaviors.

In light of Appleton's (1975) and Wilson and Kelling's (1982) contributions, CPTED has developed its standards to incorporate many of the principles of prospectrefuge theory and to include efforts to minimize physical disorder. These efforts have resulted in territoriality, surveillance, access control and maintenance becoming dominant CPTED standards. 
Today, CPTED is often incorporated into community-based crime prevention strategies. Foremost among these strategies is situational crime prevention. Like CPTED, situational crime prevention focuses on reducing criminal opportunities. With strong roots in rational choice theory, situational crime prevention seeks to diminish criminal opportunities by making crime more difficult and less rewarding and by increasing an offender's risk of detection (Clarke, 1995; Cornish \& Clarke, 1986). In doing so, situational crime prevention strategies often involve altering the physical environment by applying CPTED standards.

However, situational crime prevention represents a broader approach than CPTED. Whereas CPTED focuses on the design of the physical environment, situational crime prevention may incorporate legal and management solutions into its prevention strategies. These legal and management solutions may include enforcing laws (e.g., legal solution) or rules or procedures (e.g., management solution). For example, motorcycle thefts have declined in places where motorcyclists by law are required to wear helmets (Mayhew, Clarke \& Elliott, 1989; Mayhew, Clarke, Sturman \& Hough, 1976). In such places, rational offenders are dissuaded from stealing motorcycles because doing so without wearing a helmet-something the typical offender does not carry with him or herwill increase their likelihood of detection and arrest. In addition, research shows that refund policies, a set of rules retail merchants establish to manage the return or exchange of unwanted goods, can result in a reduction of refund fraud at retail stores (Challinger, 1997)

Contrary to most CPTED interventions, situational crime prevention strategies are highly focused on preventing specific forms of crime and, consequently, often require 
problem-solving by a variety of public and private agencies. Furthermore, unlike CPTED, situational crime prevention is not focused on improving quality of life within communities by reducing fear of crime. Despite these differences, CPTED is often creatively applied in many situational crime prevention strategies (Glazer, 1987; La Vigne, 1997; Painter \& Farrington, 1997; Poyner \& Webb, 1987). For example, Poyner and Webb (1987) studied the prevalence of robberies and purse-snatchings at Lisson Green, a London public-housing estate. They discovered that restricting access to and egress from buildings by removing walkways that linked them significantly reduced the number of robberies and purse-snatchings (Poyner \& Webb, 1987). This situational crime prevention strategy takes advantage of CPTED's access control standard.

\section{CPTED Dominant Standards: Territoriality, Surveillance Maintenance \& Access Control}

In order to improve quality of life, which requires reducing fear of crime, CPTED adheres to certain environmental design standards. As previously mentioned, the most prominent of these standards are territoriality, surveillance, access control and maintenance (Cozens, Saville\& Hillier, 2005; Crowe, 1991; Parnaby, 2006). Ideally, these standards "act in concert to use physical attributes to separate public, public-private and private space, to define ownership and define acceptable patterns of usage, in addition to promoting opportunities for surveillance" (Cozens, Saville \& Hillier, 2005, p. 331). Due to this complementary relationship, these design standards are commonly employed and evaluated together as a package. Table 1 provides each design standard's underlying objective and recommended adjustments to the environment. This table is followed by a more detailed description of each CPTED standard. 
Insert Table 1 about here

"Territoriality" aims to promote a sense of ownership and facilitate proprietary concern (Cozens, Saville \& Hillier, 2005; Crowe, 1991). Personalization design elements, such as artwork and landscaping, are often used to achieve these goals. Features such as fences, landscape design and signage also help define the difference between private and public property and in doing so are thought to facilitate a sense of ownership (Hedayati, Abdullah, Razak \& Maghsoodi, 2012a, 2012b; Sakip, Johari \& Salleh, 2012; Sutton, Cherney \& White, 2008).

"Surveillance" promotes an individual's ability to have clear views of his or her surroundings. Ultimately, this ability minimizes the availability of hiding places that offenders can use in wait of an innocent bystander. To promote surveillance, see-through fencing and lighting are often utilized; the placement of plants and walkways are also considered (Cozens, Saville \& Hillier, 2005; Crowe, 1991). Moreover, of utmost importance to upholding CPTED's surveillance standard is to ensure that physical disorder does not obstruct a user's visibility.

"Access control" involves constructing a design that manages the safe usage and movement of individuals into and out of a space, with a focus on decreasing opportunities for illegitimate use (Paranaby, 2007). Places with defined routes and entrances and exits that provide safe and convenient movement are valued. Other design features of access control include low fencing or signage. These elements are classified as symbolic barriers because they do not pose real obstacles to access and egress but, through increasing perceptions of risk, may dissuade the misuse of a space (Perkins et al., 1993). 
Lastly, "maintenance" refers to all efforts required to uphold a tidy and orderly appearance of a space. This may involve removing debris and graffiti as well as maintaining plants. Maintenance is an especially important standard to uphold because without it territoriality, surveillance and access control are critically jeopardized. For example, maintenance promotes unobstructed sightlines required to ensure visibility. It also helps create an attractive public space that is perceived to be under the care of an individual or a group of individuals. In this way, maintenance helps facilitate the image of ownership related to CPTED's territoriality concept. Additionally, maintenance supports CPTED's access control concept by allowing unhindered access and egress.

\section{The Impact of CPTED on Crime and Fear of Crime: An Empirical Review}

The primary argument of CPTED is that its alterations to the environment, guided by its design standards, are able to achieve reductions in crime as well as fear of crime within communities. In both situations, the argument is that CPTED affects individuals' perceptions of the physical environment. From an offender's perspective, these perceptions affect rational offenders' decisions to commit criminal acts. Alternatively, from a non-offender's or potential victim's perspective, these perceptions affect fear of crime.

The impact of CPTED on crime, as opposed to fear of crime, in communities is the focus of most empirical examinations of CPTED (Armitage, 2000; Casteel \& PeekAsa, 2000; Cozens, Saville \& Hillier 2005; Hendricks, Landsittel, Amandus, Malcan, \& Bell, 1999; Morrow \& Hutton, 2000; Welsh \& Farrington, 2004). However, many of these studies utilize (experimentally) weak designs which call into question the veracity of their findings (Bickman, Maltz \& Lavrakas, 1977). For example, many CPTED studies 
use a pre-posttest intervention design without a control group (Clifton, 1987; Erickson, 1998; Figlio \&Aurand, 1991; Hunter, 1990). In doing so, the impact CPTED has on crime cannot be evaluated separately from the influence of extraneous risk factors such as general crime trends (Casteel \& Peek-Asa, 2000). In other words, this type of design does not test whether the difference in crime between the pre-intervention and postintervention periods would have occurred in the absence of the intervention (i.e., CPTED). Despite this shortcoming, many CPTED intervention tactics are able to provide preliminary evidence of CPTED's ability to reduce crime (Casteel \& Peek-Asa, 2000; Cozens, Saville \& Hillier 2005; Hendricks et al., 1999; Welsh \& Farrington, 2004). Unsurprisingly, CPTED has been found to be especially effective in reducing crimes in which offenders rely on the physical environment to provide concealment and offer a quick escape such as burglary, robbery, assault and vandalism (Casteel \& Peek-Asa, 2000; Cozens, Hillier \& Prescott, 2001; Kushmuk \& Whittermore, 1981; Ward, 1973). In addition, empirical assessments of the impact of CPTED on fear of crime - a main outcome that scholars invoke as "malleable" under a CPTED framework - are fairly mixed. Among this research, CPTED evaluations that focus on assessing the impact of one CPTED standard on fear of crime are generally more successful in finding a negative relationship than evaluations of CPTED interventions where multiple standards are enforced. In particular, negative relationships are most consistently observed in studies that analyze the effects of territoriality, surveillance or maintenance on fear of crime (Braga, 2008; Brower, 1980; Brower, Dockett \& Taylor, 1983; Brown \& Werner, 1985; Farrington \& Welsh, 2002; Hinkle, 2005; Nasar \& Fisher, 1992; Sampson \& Raudenbush, 2004; Sloan, Fisher \& Wilkins, 1995). 
Some scholars question the validity of findings from studies that evaluate CPTED's various standards individually (Schneider \& Kitchen, 2002). For example, according to Schneider and Kitchen (2002), in many cases, "the physical, management and community organizational interventions... are woven together in complex ways that defy individual analysis" (p. 158). To further emphasis this point, Schneider and Kitchen (2002) comment that “it would be as difficult as untangling a spider's web to evaluate the effectiveness of specific place-based crime prevention measures" (p.158). In part, it is exceedingly difficult to evaluate the effectiveness of individual CPTED standards to reduce fear of crime because of their interconnectedness. In addition to this difficulty, the fact that many CPTED interventions do not enforce one design standard but multiple makes studying the effectiveness of individual design standards less relatable to realworld applications of CPTED compared to evaluating the effectiveness of CPTED standards as a package.

Furthermore, research on environmental cues, such as those introduced by Appleton's (1975) prospect-refuge theory, offer indirect support of CPTED's ability to reduce fear of crime (Appleton, 1975; Nasar \& Fisher, 1992: Nasar \& Jones, 1997). For example, Appleton (1975) and others have linked the number of available hiding places for offenders, known as refuge, to elevated levels of fear of crime (Nasar \& Fisher, 1992; Nasar \& Jones, 1997). In this way, CPTED's ability to reduce fear of crime is implied through its ability to reduce the number of available hiding places for offenders by implementing, most notably, its surveillance and maintenance design standards.

Lastly, studies that investigate the extent to which CPTED standards are enforced by residents and compare these findings to residents' levels of fear of crime have not 
consistently found support for CPTED's ability to reduce fear of crime (Abdullah, Marzbali \& Tilaki, 2013; Hedayati et al., 2012a; Minnery \& Lim, 2005). Rather, these studies provide evidence that CPTED may influence fear of crime through other channels. For example, finding no direct relationship between CPTED and fear of crime, Hedayati et al. (2012a) used structural equation analysis and discovered a negative indirect relationship through individuals' prior victimization experiences.

Although this mixed body of research may seem discouraging, the impact of CPTED on fear of crime is greatly affected by the ways in which both these concepts have been measured - an issue which has been greatly debated over the decades of research. This debate has resulted in the inconsistent measurement of CPTED and fear of crime, making across study comparisons difficult. For example, in their analyses on the impact of CPTED on fear of crime, both Minnery and Lim (2005) and Hedayati et al. (2012a, 2012b) identify and define CPTED standards and fear of crime differently.

However, progress is being made toward developing a standard CPTED scale of measurement (Abdullah, Marzbali \& Tilaki, 2013; Hedayati et al., 2012a, 2012b; Minnery \& Lim, 2005). In part, this progress is possible because of researchers' unifying understanding of CPTED's goals. In other words, a common conceptual understanding of CPTED has helped facilitate a movement toward developing a standard CPTED scale of measurement. Unlike CPTED research, fear of crime research is not motivated by a unifying conceptual understanding of the construct of fear of crime; no comprehensive theoretical model of fear of crime exists (Alper \& Chappell, 2002). 


\section{Understanding Fear of Crime}

As suggested, there is substantial heterogeneity in how researchers interpret and measure fear of crime. This heterogeneity is emphasized in Ferraro and LaGrange's (1987) evaluation of fear of crime research. As part of this evaluation, Ferraro and LaGrange (1987) investigated the ways in which fear of crime was measured by creating a two-dimensional classification system. The first dimension includes the level at which crime perceptions were evaluated: general (community-oriented) or personal (selforiented). The second dimension includes the type of crime perception: cognitive (e.g., focuses on the likelihood of an event occurring) or affective (e.g., focuses on the emotion associated with an event).

Ferraro and LaGrange (1987) understood fear of crime as an affective (or psychological) state. However, recent scholarship has started to recognize the multidimensional character of fear of crime. This recognition has led to advances in, among other things, how fear of crime is defined (Doran \& Burgess, 2012; Ferraro \& LaGrange, 1987; Jackson, 2004, 2006; Skogan, 1986; Vanderveen, 2006). In particular, fear of crime definitions are now beginning to include both cognitive and affective appraisals of crime (Vanderveen, 2006). However, the primary interest of this present study is the ways in which both of these appraisals are interpreted in the context of the physical environment. In relevant literature, cognitive appraisals of crime often include an individual's perception of safety and his or her perceived risk of victimization (Hedayati et al., 2012a, 2012b; LaGrange, Ferraro \& Supancic, 1992; Nasar \& Jones, 1997; Rountree \& Land, 1996; Toet \& van Schaik, 2012). In addition, this literature also 
includes the more traditional affective appraisal of an individual's fear of victimization (Park, 2008; Warr, 1990).

Thus, the concept of fear of crime includes several elements, most notably perceptions of safety, risk of victimization and fear of victimization. These elements are related but are thought to be conceptually distinct (Dubow, McCabe \& Kaplan, 1979; Ferraro \& LaGrange, 1987; Rountree \& Land, 1996; Vanderveen, 2006). Researchers may be better able to capture the concept of fear of crime if they use all these elements to measure it rather than only one.

Additionally, a more valid and useful measurement of these fear of crime elements is how they relate to specific crime types, rather than to crime in general (Ferraro \& LaGrange, 1987; Gabriel \& Greve, 2003; Jackson, 2004,2006; Rountree \& Land, 1996). Relevant research on CPTED commonly examines its impact on the following crime types: robbery, physical assault, harassment and sexual assault. These crime types are common in CPTED research because they can occur outside and are therefore amenable to CPTED standards (Branas et al., 2011; Casteel \& Peek-Asa, 2000; Kushmuk \& Whittermore, 1981; Troy, Grove \& O’Neil-Dunne, 2012). Furthermore, as discussed in an earlier section, offenders are able to take advantage of their surrounding physical environments to perpetrate these crimes. The same features of the environment that aid offenders to commit these crimes also influence non-offenders' levels of fear of crime.

The literature on fear of crime suggests that it is related to many things that generally cluster into individual and situational-level factors. For instance, an individual's sex and age have been consistently found to be related to one's fear of crime response, 
with higher levels of fear of crime found among women and the elderly despite being the least victimized groups (Baumer, 1985; Bennett \& Flavin, 1994; Flynn, Slovic, \& Mertz, 1994; Hindelang, Gottfredson \& Garofalo, 1978; Perkins \& Taylor, 1996). In addition, an individual's hometown has also been linked to one's level of fear of crime. Research shows that those who primarily live in urban environments are more likely to have higher levels of fear of crime than those who primarily live in rural or suburban environments (Lab, 2014; Toseland, 2002; Will, 1995; Will \& McGrath, 1995). This may be because crime is more prevalent in urban areas than it is in other places. Lastly, many studies have reported that those who have the highest levels of fear of crime are minority individuals and those of low socioeconomic status (Bennett \& Flavin, 1994; Parker \& Ray, 1990; Skogan \& Maxfield, 1981; Smith \& Lab, 1991; Will \& McGrath, 1995). For example, Will and McGrath's (1995) analysis on neighborhood fear and the underclass found that non-whites had higher levels of neighborhood fear than whites. ${ }^{2}$ However, when differentiating participants by class status, the effect of a respondent's race was no longer significant. Regardless of place, Will and McGrath (1995) found that the underclass were more fearful than the non-poor and that this effect was the strongest for women.

The relationship between an individual's victimization history and his or her level of fear of crime is less understood. Some research indicates that victims of crime have higher levels of fear of crime than non-victims (Garofalo, 1979; Gomme, 1986; Keane, 1995; Lumb, Hunter \& McLain, 1993; Skogan, 1987). However, fear of crime may not

\footnotetext{
2 Will and McGrath (1995) measured neighborhood fear as a binary variable. Participants were asked the following question: "Is there any area right around here where you would be afraid to walk alone at night?" (p. 168) Affirmative responses were coded as 1 and negative responses as 0.
} 
have such a clear relationship with one's actual victimization experiences. Many other studies have failed to find any relationship between past victimization experiences and fear of crime (Ferraro, 1995, Garofalo, 1979; McGarrell, Giacomazzi \& Thurman, 1999; Perkins \& Taylor, 1996). Interestingly, research provides evidence that an individual's indirect victimization experiences may play a leading role in affecting his or her level of fear of crime (Arnold, 1991; Hale, 1996; Skogan \& Maxfield, 1981). For example, Arnold (1991) found that an individual's indirect, rather than direct, victimization experiences played a more significant role in influencing his or her level of fear of crime. Whereas some individual characteristics equally pertain to all elements of fear of crime, such as those previously discussed, others do not. An individual's perceived locus of control is a case of this phenomenon; it is more closely related to one's perceived risk of victimization than to the other elements of fear of crime. Rotter (1966) suggested that one's locus of control, internal versus external, is related to the extent to which one believes he or she can control a dangerous situation. Those with internal loci of control may believe they can control a dangerous situation, whereas their counterparts likely view the same situation as beyond their control. Subsequent research has supported Rotter's (1966) claim, finding perceptions of risk lower in individuals who believe themselves to be able to take control over a risk or hazard (Prociuk, Breen \& Lussier, 1976; Riechard \& Peterson, 1998; Slovic, 2010).

Individual characteristics play an important role in influencing fear of crime. However, of particular interest to this study are the situational-level factors linked to CPTED's alterations to the physical environment that affect an individual's level of fear of crime. Fear of crime has been demonstrated to be unevenly distributed over space and 
time (Herzog \& Bryce, 2007; Nasar \& Jones, 1997; Spelman, 1993; Stamps, 2005; Wilson \& Kelling, 1982). For example, some areas, such as vacant lots (e.g., Spelman, 1993), and times of day, such as nighttime hours (e.g., Nasar \& Jones, 1997), are associated with elevated fear of crime responses. These responses are thought to be influenced by a repository of mental images that individuals store of their surroundings, which are developed by ongoing experiences with the environment. Furthermore, these images are associated with perceptions about, among other things, safe and unsafe areas (Hanyu, 1993; Kaplan, 1979; Nasar \& Jones, 1997). In other words, these mental images allow individuals to quickly identify components of their surroundings that act as environmental cues signaling safe and unsafe areas. This process, in turn, influences individuals' levels of fear of crime. In theory, these mental images (linked to individuals' levels of fear of crime) help individuals quickly formulate predictions of what will happen to them in a particular environment, evaluate its consequences and formulate a response (Kaplan, 1979; Liska, Sanchirico \& Reed, 1988; Nasar \& Jones, 1997; Warr, 1990).

As suggested, this present study is particularly interested in environmental cues that influence fear of crime assessments that not only are affected by CPTED's alterations to the built environment but are also within this study's control to manipulate. In this regard, research on perceptions of physical disorder, territorial features and the related concepts of prospect, concealment and entrapment are able to provide insight into the role environmental cues play in influencing fear of crime. Armed with this knowledge, and facilitated by the conceptual understanding of CPTED, the ability of CPTED standards to decrease fear of crime can be better understood. 


\section{Perceptions of Disorder}

Numerous studies have assessed the relationship between perceptions of disorder and fear of crime (Covington \& Taylor, 1991; Hinkle \& Weisburd, 2008; Markowitz, Bellair, Liska \& Liu, 2001). Many of these studies support the argument that residents who perceive more disorder related cues (e.g., graffiti, trash and overgrown foliage) in their immediate surroundings perform worse on fear of crime assessments than their counterparts. Here, disorder acts as environmental cues which signal to residents that deviant behaviors are unable to be controlled. (Wilson \& Kelling, 1982). In this way, disorder serves as a signal to identify dangerous areas which subsequently affects fear of crime assessments. However, some research has found that individuals who are more readily exposed to disorderly environments can become desensitized to the presence of disorder (Harcourt, 2001; Taylor, Shumaker \& Gottfredson, 1985). In such cases, perceptions of disorder are not shown to illicit the reactions previously described. Yet, in the aggregate, research is largely supportive of a positive relationship between perceptions of disorder and fear of crime.

Studies that assess perceptions of disorder generally identify stronger positive relationships with fear of crime than studies that collect data on the level of disorder through systematic observations of social space (Perkins \& Taylor, 1996; Sampson \& Raudenbush, 2004; Taylor, 1996). Although this dichotomy is curious, it does not undermine the utility of perception-based research. In fact, much research has found perceptions of disorder and objective measures of disorder to be highly correlated (Perkins, Meeks \& Taylor, 1992; Sampson \& Raudenbush, 2004; Taylor, Shumaker \& Gottfredson, 1985). Furthermore, perceptions of disorder reflect a psychological 
construct that is more relatable to the cognitive and affective elements of fear of crime. In regards to CPTED, recall that Jeffery (1977) emphasized the ability of environmental cues, such as physical disorder, to trigger individuals to formulate perceptions of their surroundings that are used in cognitive processes that affect behavior. Although not explicitly stated by Jeffery (1977), perceptual, as well as affective, elements of fear of crime are influenced by these cognitive processes. Therefore, it would seem that attention to perceptions of disorder rather than to objective measures of disorder more wholly reflects the mechanisms by which CPTED influences fear of crime.

However, not all elements of disorder can be easily manipulated for purposes of experimentation. Disorder consists of both physical and social elements. Physical disorder, previously introduced, includes environmental features that reflect neighborhood dilapidation such as graffiti and debris (Skogan, 1990). Moreover, social disorder consists of behavioral issues within communities such as panhandling and loitering (Skogan, 1990). Unlike social disorder, physical disorder can be more easily experimentally manipulated for research purposes. In addition, it is arguably less likely to be misinterpreted by respondents when viewed in a picture (the medium of this study). Similar to research that makes no distinction between the types of disorders (physical or social), research deciphering the effects of physical disorder from social disorder have fairly consistently found a negative relationship with fear of crime (Covington \& Taylor, 1991; Perkins \& Taylor, 1996; Wikström, 1990).

CPTED has the ability to affect perceptions of disorder through its maintenance standard. Recall that CPTED's maintenance standard requires environments to be free of physical disorder. In this way, CPTED affects perceptions of physical disorder by 
reducing the number of disorder-related cues in the environment. In doing so, CPTED is able to reduce fear of crime by altering, for example, expectations linked to individuals' perceptions of disorder. These expectations include how others will act in a given environment which aid individuals in defining safe and unsafe places. Traditional urban greening practices also focus on improving disorderly conditions by removing disorderrelated cues and, in this way, are thought to similarly affect perceptions of disorder and fear of crime.

\section{Territorial Features}

Territorial features, such as personalization items and clear demarcation between public and private spaces, have also been shown to influence fear of crime. In particular, this body of research has shown that residents and non-residents alike use territorial markers as indicators on how others will receive them (Brower, 1980; Greenbaum \& Greenbaum, 1981; Taylor \& Harrell, 1996). Research has found individuals to have lower levels of fear of crime in areas that contain territorial features, suggesting that perceptions of ownership and proprietary concern may play a leading role in the interpretations individuals make about their surroundings (Abdullah, Hedayati, Haron, Bahauddin, \& Maghsoodi, 2013; Brower, Dockett \& Taylor, 1983; Brown \& Werner, 1985; Newman, 1972; Pollack \& Patterson, 1980; Taylor, Shumaker\& Gottfredson, 1985). For example, according to CPTED, territorial features trigger the perception that a location is under the care of an individual or group of individuals and, consequently, that deviant acts will not go unpunished. Interpreted in this way, territorial features function as environmental cues that signify safe areas. Such cues, as previously explained, are associated with lower levels of fear of crime. Research on territorial features also 
suggests that more threatening environments, such as those which are disorderly, require more territorial features to decrease fear of crime (Brower, Dockett \& Taylor, 1983).

CPTED's territoriality standard promotes the use of territorial features and, consequently, takes advantage of the opportunity to optimize reductions in fear of crime. Contrastingly, traditional urban greening practices do not focus on improving the environment in this way. Rather, the enforcement of territoriality may be an unintended consequence. For example, the arrangement in which trees or bushes are planted may, inadvertently, aid in providing a distinction between public and private property, consequently facilitating the concepts of ownership and proprietary concern associated with territoriality. Although this arrangement may be intentional its consequence, facilitating CPTED's territoriality concept, is not. The effect of urban greening's unintended enforcement of territoriality is arguably not equivalent to its explicit enforcement by CPTED. CPTED includes more territorial features and in doing so capitalizes on the opportunity to reduce fear of crime.

\section{Prospect, Concealment and Entrapment}

Related to Appleton's (1975) prospect-refuge theory, another set of physical cues that individuals use to infer what will happen to them in a particular environment are those associated with the interrelated concepts of prospect, concealment and entrapment. Prospect refers to an individual's ability to see into a space. In places like vacant lots, this ability is impaired by physical disorder (e.g., overgrown foliage and debris). Physical disorder also provides concealment for offenders to hide in wait of a passerby who will not be able to anticipate their advances. In addition, physical disorder impairs an individual's ability to quickly and easily escape an offender's attack by obstructing his or 
her access to and egress from a space. The inability to quickly and easily escape a potential offender is known as entrapment.

Collectively, individuals interpret features of the environment that impair prospect (hereon referred to as blocked prospect), provide hiding places for offenders (concealment) and impede escape (entrapment) as cues signifying dangerous places. Unsurprisingly, individuals exposed to environmental conditions that facilitate blocked prospect, concealment and entrapment have, on average, heightened levels of fear of crime (Day, 1994; Fisher, Sloan \& Wilkins, 1995; Nasar \& Fisher, 1992; Nasar \& Jones, 1997).

Vacant lots' disorderly conditions readily provide opportunities for blocked prospect, concealment and entrapment. Traditional urban greening practices and CPTED both seek to rectify disorderly conditions by focusing on lot maintenance. In particular, traditional urban greening practices' focus on maintenance alone will arguably not achieve the greatest returns in reducing opportunities for concealment and entrapment. Maintenance that is reinforced by CPTED's surveillance and access control standards help optimize reductions in concealment and entrapment by promoting visibility (i.e., prospect) and easy access to and egress from a space, respectively. In doing so, the combined effect of enforcing maintenance, surveillance and access control is likely better able to reduce fear of crime than that which would likely be achieved by enforcing maintenance alone. This specified attention to surveillance and access control, in addition to maintenance, is what distinguishes CPTED from traditional urban greening practices. 


\section{CPTED \& Fear of Crime: Greening Vacant Lots}

Vacant lots are common features of cities and their surrounding neighborhoods that facilitate fear of crime (Spelman, 1993; Wilson \& Kelling, 1982). Methods to alleviate fear of crime deserve our attention due to its association with debilitating outcomes that affect an individual's social, mental and physical health and, on a larger scale, the vitality of his or her community (Green, Gilbertson \& Grimsley, 2002; Morrall et al., 2010; Ross \& Mirowsky, 2001; Wilson \& Kelling, 1982). These debilitating outcomes negatively affect residents' quality of life (Blakely \& Snyder, 1997; Green, 2002).

One way in which community officials attempt to reduce fear of crime, and in doing so increase quality of life, is to transform vacant lots into green space (Baltimore Green Space, 2013; Greening of Detroit, 2014; Pennsylvania Horticultural Society, 2014; Urban Green, 2014). Although these efforts are admirable, traditional urban greening practices likely do not take advantage of opportunities to reduce fear of crime. Rather, it has been argued that the implementation of CPTED standards into greening practices will capitalize on this opportunity. CPTED's territoriality, surveillance, access control and maintenance standards are specifically designed to reduce fear of crime by, among other things, reducing disorder-related cues, introducing territorial markers, improving visibility, eliminating hiding places for offenders and providing easy access to and egress from a space.

In part, urban greening provides an ideal framework for the implementation of CPTED because it is already organized around one of CPTED's staple standards: maintenance. Given the interconnectedness of CPTED standards, introducing 
territoriality, access control and surveillance into traditional urban greening practices could easily be achieved. This effort is an important step towards discovering urban greening techniques that are able to achieve greater reductions of fear of crime than traditional approaches. These new techniques also have a greater potential to help alleviate residents from the debilitating social, mental and physical conditions that suppress their quality of life and the welfare of their communities.

The present study will test the following hypotheses:

Hypothesis 1: On average, participants who view either a greened lot or a CPTED lot will report lower levels of fear of crime than participants who view a disorderly lot.

Hypothesis 2: On average, participants who view a CPTED lot will report lower levels of fear of crime than participants who view a greened lot relative to a disorderly lot.

Due to the interconnectedness of CPTED standards, this study evaluates CPTED as a package. This study will test these hypotheses using a computer program to adjust an image of a vacant lot to meet three conditions: A disorderly lot; 2) A greened lot; and 3) A CPTED lot. These three images represent the three levels of the study's independent variable and will be randomly distributed in the form of questionnaires to undergraduate students. Additionally, to facilitate fear of crime as a collective concept that includes both cognitive and affective elements, this questionnaire will assess perceptions of safety, risk of victimization and fear of victimization in relation to four previously identified crime types: robbery, physical assault, harassment and sexual assault. This study will then use Ordinary Least Squares Regression (OLS) to test its hypotheses. 


\section{Chapter 3: Methods}

\section{Sample}

The present study collected its data from a convenience sample of undergraduate students enrolled at a large East Coast university. This sample consisted of students who were enrolled in one of eight criminal justice classes whose professors agreed to set aside class time for the purpose of this study. In particular, these classes included a range of introductory to advanced courses. There were two exclusion criteria for participation. First, students that had previously participated in this study were not allowed to participate a second time. This precaution was necessary given that this study required that students be surveyed from multiple classes. Lastly, this study also excluded students who were younger than 18 years of age and required the permission of a parent or guardian to participate. A total of 551 students were surveyed. Due to missing data, 523 participants were retained for analysis. ${ }^{3}$

The purpose of sampling students from multiple classes was to help ensure sufficient sample sizes for each of the study's three conditions which represent the three levels of the independent variable: a disorderly lot, a greened lot and a CPTED lot. Extant literature proposes many different methods for determining sample size including power analytic techniques and accuracy in parameter estimation (AIPE) (Cohen, 1988; Kelley \& Maxwell, 2003; Maxwell, 2000). Many of these methods require making assumptions about the sample such as its expected effect size as well as its corresponding population standard deviation and mean. By studying similar research, scholars are often able to

\footnotetext{
${ }^{3}$ This study did not pursue imputing missing data (or other estimation techniques) due to the low number of missing cases.
} 
make well-informed assumptions. However, the utility of these methods to determine sample size becomes suspect when researchers, like in this present case, are unable to turn to past research to make educated assumptions about the likely effect size, for example. For this reason this study did not attempt to calculate an appropriate sample size. Rather, it sought to optimize its sample size by drawing data from students enrolled in multiple different classes.

This study's sample is not without its limitations. A chief limitation of student samples is the fact that students represent a select group that is not representative of the general population. Therefore, student samples limit a study's external validity. For example, participants in college-drawn student samples are more likely to come from affluent backgrounds (Sears, 1986; Wells, 1993). Consequently, these samples are less likely to capture data from minority and lower-class individuals who tend to be underrepresented in many U.S. colleges. Despite this limitation, a student sample is reasonable for this study's hypotheses because it allows the opportunity to begin building a foundational understanding of an unexplored research area without the costs to time and financial resources needed to procure a wider demographic of participants. In other words, the primary objective of this study is not to strive to achieve external validity. Rather, its primary objective is to begin a discussion on the potential utility of improving traditional urban greening practices in order to optimize reductions in fear of crime and, in doing so, determine whether a large-scale study utilizing a sampling technique that captures participants that are representative of a future undetermined target population is worthwhile. 


\section{Procedure}

The primary investigator asked students during their lecture hour to participate in a study on the impact of certain environmental features on fear of crime by completing a nine-page questionnaire approved by the university's Institutional Review Board (IRB). At this time, the primary investigator read a script to the potential participants that contained the purpose of the study and a brief overview of the questionnaire (see Appendix A).

Each questionnaire had a number located in the top right-hand corner of every page. This number identified each questionnaire as containing either an image of a disorderly lot (identified as 1), a greened lot (identified as 2) or a CPTED lot (identified as 3). This was the only difference across questionnaires. This study used these three numbers $(1,2$ and 3$)$ to simulate random assignment. To do so, this study used a computer program (Research Randomizer) to generate a random sequence of these three numbers. The primary investigator arranged the questionnaires in accordance to this random number sequence. This procedure helped ensure that all three numbers appeared approximately the same number of times and that roughly equal numbers of participants were in each condition.

Moreover, prior to distributing the questionnaires and consent forms, the primary investigator instructed participants to not sign either document in order to protect their anonymity and to read the consent form before completing the questionnaire. After providing this instruction, the primary investigator (and her research volunteers) then distributed the questionnaires along with consent forms. Completing the questionnaire indicated that participants did not already participate in the study, were at least 18 years 
of age, had read the consent form and agreed to participate in this research study. A total of 551 out of 826 individuals agreed to participate, making this study's refusal rate approximately $33.29 \% .^{4}$

\section{Environmental Simulation: A Justification for using Images}

As mentioned, this study utilized a computer program to adjust a photograph taken of a vacant lot (see Figure 1) to meet the following conditions: 1) A disorderly lot; 2) A greened lot; and 3) A CPTED lot. A disorderly lot is one that has physical manifestations of neighbor dilapidation (e.g., trash and overgrown foliage), while a greened lot is one that has been transformed according to traditional urban greening standards. Lastly, a CPTED lot is one that incorporates CPTED standards into the traditional greening process.

Using pictures to represent these three conditions is not only cost-effective, but also reduces potential confounders. This study was able to minimize (if not eliminate) confounding variables by creating a template from which adjustments were made to simulate each condition (i.e., a disorderly lot, a greened lot and a CPTED lot). Because all images used the same basic template, one can be more confident that any observed differences across conditions in respondents' levels of fear of crime are reflective of actual treatment effects rather than the result of unaccounted for differences across images. This confidence would not be so easily obtained in a "real-world" application of

\footnotetext{
4 This study's refusal rate is not atypical for student samples (Jans \& Roman, 2007). That being said, this study suspects that its high refusal rate was partially due to the time during classes that questionnaires were distributed. Questionnaires were distributed either at the end of class or at the beginning of class. The time at which questionnaires were distributed was dictated by professors' preferences. Students were more likely to refuse to participate in this study when questionnaires were distributed at the end of class than at the beginning of class. In particular, the refusal rate was $43.8053 \%$ for the six classes where questionnaires were distributed at the end of class and $20.8556 \%$ for the remaining two classes where questionnaires were distributed at the beginning of class.
} 
this study. For example, in a real-world scenario each lot would only be able to represent one condition: a disorderly lot, a greened lot or a CPTED lot. It is likely that each lot would have unique features, such as its distance to schools, parks and businesses, which would affect individuals' levels of fear of crime (Branas et al., 2011; Heckert \& Mennis, 2012). These features are likely to be ignored (or improperly controlled), obscuring the identification of a (valid) treatment effect.

The high level of control offered by images is something that real-world environments simply cannot offer. For this reason, many studies have utilized images to assess the impact of environmental conditions on fear of crime (Andrews \& Gatersleben, 2010; Austin \& Sanders, 2007; Cinar \& Cubukcu, 2012; Herzog \& Flynn-Smith, 2001; Jorgensen, Ellis \& Ruddell, 2013; Stamps \& Smith, 2002; Wang \& Taylor, 2007). For example, Austin and Sanders (2007) exposed participants to photographs taken of graffiti to assess whether viewing these images affected perceptions of safety. However, researchers need not use images to gain this high degree of control. This ability is a defining feature of what is referred to as "artificial digital environments." Artificial digital environments are environments that are created by using technology (e.g., cameras or computer software) to simulate conditions similar to that of the real-world. Artificial digital environments include static media (e.g., photographs and $360^{\circ}$ panoramic images) as well as dynamic media (e.g., virtual environments).

Of course, a primary benefit of real-world environments is their ability to offer "ecological validity." Ecological validity refers to the extent to which the methods, materials and setting of the study approximate real-world conditions (Schmuckler, 2001; 
Shadish, Cook \& Campbell, 2002). Improving ecological validity can improve external validity which is concerned with the generalizability of a study's results.

In their analysis on the effect of disorder on fear of crime in real and virtual environments, Toet and van Schaik (2012) explain that for an artificial digital environment (e.g., photographs and virtual environments) to be considered ecologically valid it must evoke "cognitive, emotional and affective user responses that are similar to those that would be evoked by a real equivalent" (p. 260). Toet and van Schaik (2012) then explain that studies that utilize artificial digital environments do not need to fulfill all aspects of ecological validity (hereon referred to as "full ecological validity") in order to assess the influence of physical interventions in the built environment, such as environmental cues and urban design, on human behavior (i.e, cognition, emotion and affect). Said differently, artificial digital environments do not have to evoke similar responses for all human behaviors to those thatwould be evoked by a real-world equivalent. Rather, it is permissible, in most circumstances, for artificial digital environments to affect only some human behaviors, such as fear of crime, in a similar way as their real-world equivalents and in doing so achieve "partial ecological validity" (van Hagen, 2011).

Meta-analyses comparing static media to evaluations gathered from their equivalent real-world environments offer considerable support of the ability of responses obtained by viewing images to achieve partial ecological validity (Palmer \& Hoffman, 2001; Stamps, 1990; Stamps, 2010). In particular, using the key words "visual simulation validity," Stamp (2010) identified 33 articles in Science Citation Index and Google Scholar which together included more than 3,511 participants and 451 (both real and digital) 
environments. From these articles, Stamp identified a strong correlation $(r=.86)$ between responses obtained from viewing (color) images and responses from similar real-world environments.

Despite this support, there are some noteworthy limitations of using photographs. For example, unlike real or virtual environments, images are highly dependent on viewpoint (Palmer \& Hoffman, 2001). Images only allow individuals to view one angle of a location. A common solution to this issue of limited viewpoint is computer simulated $360^{\circ}$ panoramic images. Research that links aspects of the physical environment to passengers' levels of fear of crime in railway stations commonly use these images (Cozens, Neale \& Hillier, 2003; Cozens, Neal, Hillier \& Whitaker, 2004; Cozens, Neal, Whitaker \& Hillier, 2003).

For this study, a $360^{\circ}$ panoramic image would require systematically stitching together separate images using a computer program. This process alone is very tedious; images must be precisely stitched together to create the impression of seamlessness. This impression is critical to building an artificial digital environment that is realistic or, in other words, similar to its real-world equivalent. This task is made even more difficult when, in this process of stitching together images, one must account for the large amount of editing that must be performed for this $360^{\circ}$ panoramic image to meet the three lot conditions of this study. This editing process would likely jeopardize attaining seamless $360^{\circ}$ panoramic images. In addition, $360^{\circ}$ panoramic images have not yet been compared against responses obtained from equivalent real-world environments. Therefore, no empirically-based argument can be made for using $360^{\circ}$ panoramic images over regular 
photographs. For these reasons this study did not pursue constructing $360^{\circ}$ panoramic images.

In addition, images, including $360^{\circ}$ panoramic images, are often criticized as not fully capturing the dynamics of a real-world environment. In particular, common criticisms of images include lack of ambient sounds and the inability to walk through and interact with an environment. These criticisms are often addressed through developing virtual environments. Recent research has used virtual environments to study the impact of environmental cues on fear of crime (Park, 2008; Park et al., 2011, 2012). Studies that compare the responses received from a simulated environment to their real-world counterpart have garnered some support for the ability of virtual environments to affect human behavior, such as fear of crime, in a similar way (Bishop \& Rohrmann, 2003; Houtkamp \& Junger, 2010; Schwebel, Gaines \& Severson, 2008; Toet \& van Schaik, 2012). Unfortunately, creating a virtual environment is beyond the financial capability and time-constraint of this study. ${ }^{5}$

\section{$\underline{\text { Measures }}$}

\section{Dependent Variables}

This study uses three fear of crime elements to assess the fear of crime concept: perceptions of safety, risk of victimization and fear of victimization. As previously discussed, a more valid and useful measurement of these fear of crime elements is how they relate to specific crime types, rather than to crime in general (Ferraro \& LaGrange, 1987; Gabriel \& Greve, 2003; Jackson, 2004, 2006; Rountree \& Land, 1996). The present study chose to focus on the crimes of robbery, physical assault, harassment and

\footnotetext{
${ }^{5}$ The cost of creating a virtual environment was estimated to be around $\$ 10,000$ and would have taken approximately one year to design.
} 
sexual assault based upon their ability to be conducted outside and their prevalence in relevant research on CPTED (Branas et al., 2011; Casteel \& Peek-Asa, 2000; Kushmuk \& Whittermore, 1981; Troy, Morgan \& O’Neil-Dunne, 2012). Furthermore, in earlier sections it was discussed how offenders and non-offenders are influenced by features present in the environment. This discussion supports this study's focus on these crime types. Recall that the same features of the environment that influence and aid offenders to commit robbery, physical assault, harassment and sexual assault also affect nonoffenders' levels of fear of crime. For example, physical disorder provides offenders hiding places where physical and sexual assaults are able to be conducted undetected. Non-offenders interpret locations where physical disorder is prevalent as dangerous places where these and other crimes likely occur. The questionnaire provides participants with definitions of each crime type which were adapted from the Uniform Crime Report (UCR) as well as from additional non-governmental sources.

In order to develop measurement scales for these fear of crime elements, this study identified common themes in how these elements were previously measured. In part, developing scales in this way allowed this study to remain as consistent as possible with past operationalizations and measurements of fear of crime. This study then adapted each scale to fit the format of its questionnaire. Table 2 displays the descriptive statistics for these three measures for the full sample as well as for each level of the independent variable. 
Perception of Safety. Perceptions of safety are often measured by asking individuals to indicate on a Likert scale how safe they would feel walking alone at night often within the context of a particular location, such as a block or a neighborhood (e.g., National Crime Victimization Survey (NCVS), Crime Survey (CS) (formerly referred to as the British Crime Survey) and General Social Survey (GSS)). Such measures have been criticized for being limited to nighttime, not directly mentioning crime, referring to vague geographical areas (i.e. the neighborhood) and only crudely measuring intensity (Ferraro, 1995). These measures have also been criticized for asking about an activity (walking alone at night) that people rarely or never do in their daily lives (Ferraro, 1995). In an attempt to address some of these criticisms, this study asked participants to indicate on a seven-point Likert scale the extent to which they would feel safe from becoming a victim of each crime type (robbery, physical assault, harassment or sexual assault) while walking alone by or in a specific location (the pictured lot). Responses ranged from one to seven and included the following: "very safe"(1), "safe"(2), "somewhat safe"(3), “neutral”(4) “somewhat unsafe"(5), "unsafe"(6) and "very unsafe"(7).

This new perception of safety measure addresses five general criticisms. First, it is not limited to nighttime. It also explicitly mentions crime by asking respondents to report their perceived levels of safety in regards to robbery, physical assault, harassment and sexual assault. In addition, this measure refers to a concrete geographic area: the pictured location an individual randomly received. Furthermore, this study utilized a seven-point Likert scale in order to create an instrument that is better able to measure intensity. Lastly, this measure is purposefully ambiguous about the time of day an individual walks 
alone in order to better facilitate responses based on activities that are relevant to participants' daily lives.

Risk of Victimization. Risk of victimization is commonly measured by asking individuals to indicate on a Likert scale their perceived likelihood of falling victim to a specific crime (Hale, 1996; Jackson, 2006, 2011; Warr, 1985, 1987). To remain consistent with past measurements, this study also used a similar measure. This study required participants to indicate on a seven-point Likert scale how likely- at the location (picture) shown- they thought it would be that they would become a victim of each crime type (robbery, physical assault, harassment or sexual assault). Responses ranged from one to seven and included the following: "very unlikely" (1), "unlikely"(2), "somewhat unlikely"(3), "neutral”(4), "somewhat likely"(5), "likely"(6) and "very likely" (7).

Fear of Victimization. Fear of victimization is commonly measured by asking individuals to indicate on a Likert scale how afraid they are that they will become a victim of a specific crime (Ferraro, 1996; Warr, 1987, 1990 1994; Warr \& Stafford, 1983). Again, to remain consistent with past measures, this study also included a similar item. This study required participants to indicate on a seven-point Likert scale how afraid- at the location (picture) shown- that they would become a victim of each crime type (robbery, physical assault, harassment or sexual assault). Responses ranged from one to seven and included the following: "not at all afraid"(1), "not afraid"(2), "somewhat not afraid"(3), "neutral"(4), "somewhat afraid"(5), "afraid"(6) and "very afraid"(7).

This study used all 12 of its fear of crime items in a factor analysis. In essence, factor analysis is used to identify relationships among a set of items and from these 
relationships determine a reduced set of common factors (Grice, 2001, 2007). These common factors are unobserved latent constructs that hold theoretical significance (Grice, 2001, 2007; Porter \& Fabrigar, 2007). This method is commonly used in fear of crime research to understand how fear of crime items are related to one another (Ferraro, 1995; Vanderveen, 2006). Using the above fear of crime items, a factor analysis will allow this study to identify any existing factors and to create measures that reflect underlying latent constructs using factor scores.

There are two main types of factor analysis: Confirmatory Factor Analysis (CFA) and Exploratory Factor Analysis (EFA). CFA is used to test hypotheses on the relationships between observable items (or variables) and existing underlying latent constructs. Here, researchers use theory and empirical research to guide them on this relationship a priori. These hypotheses are then statistically tested. Unlike CFA, EFA explores the underlying structure of interrelated items without imposing any restrictions on the outcome (Child, 1990). In other words, researchers conducting EFA set no expectations on the nature of the items and the number of underlying latent constructs. EFA is often used when there are many competing theoretically-related reasons for determining a measurement model. Recall that there is substantial heterogeneity in how researchers interpret and measure fear of crime (Farrall, Bannister, Ditton \& Gilchrist, 1997; Ferraro \& LaGrange, 1987). As a consequence, no comprehensive theoretical understanding of fear of crime exists (Alper \& Chappell, 2002). This heterogeneity lends credence to the use of EFA in fear of crime research. For this reason, this study used EFA to identify factors related to fear of crime. 
Prior to extracting factors, it is prudent to assess whether the data are suitable for factor analysis. Factor analysis requires large samples to ensure that the correlations among variables are reliable estimates. Relatedly, it is also preferable that the ratio of subjects-to-variables is large. Although there is no hard and fast rule for these criteria, a sample size of 150 or larger and subject-to-variable ratio of 10 to 1 is generally accepted (Beavers et al., 2013). This study's sample size ( $\mathrm{N}=523)$ and subject-to-variable ratio $(\approx 43$ to 1$)$ meet these criteria. Furthermore, factor analysis requires that there are no outliers and that the relationship among pairs of variables is linear. Using scatterplots of the fear of crime items, this study validated that these conditions were upheld. Lastly, factor analysis does not require multivariate normality, however it is desirable because it improves statistical inference. Tests for normality reveal that this study's fear of crime items do not have multivariate normal distributions.

There are several other more rigorous methods for determining whether data are suitable for factor analysis. These methods include examining a correlation matrix and conducting the Kaiser-Meyer-Olkin (KMO) measure of sampling adequacy test. The Pearson correlation matrix is perhaps the most commonly used matrix to assess the interrelationships between sets of variables. This matrix assumes that variables are measured on an interval or ratio scale and that there are linear relationships between variables. The Pearson correlation matrix is not appropriate for the present analysis given the ordinal nature of its fear of crime items. In fact, the Pearson correlation matrix often underestimates the relationship between individual ordinal items and can lead to biased factor loadings (Bernstein \& Teng, 1989). For this reason, this study used a polychoric correlation matrix to assess the relationships between individual items. This technique is 
more amenable to ordinal data. It estimates the relationship between two bivariate normally distributed continuous variables measured on ordinal scales (Olsson, 1979). The assumption of bivariate normality may seem limiting, however it is only necessary that some monotonic transformation of the responses under examination exist such that their transformed versions have a bivariate normal distribution (Uebersax, 2015). Like the Pearson correlation matrix, the polychoric correlation matrix provides a statistic ranging from -1 to 1 . Scholars suggest that factor analysis should be reconsidered if few correlation coefficients exceed \pm 0.30 (Costello \& Osborne, 2005). Table 3 displays the polychoric correlation matrix. The matrix reveals high to moderate correlation coefficients among all paired items. This finding suggests not only that factor analysis is appropriate but also that these items may be united by one underlying common factor.

Insert Table 3 about here

This study then conducted KMO measure of sampling adequacy test. The KMO measure of sampling adequacy test provides a statistic ranging from 0 to 1 that reflects the proportion of variance among the variables that is shared or common. Higher values are more suggestive of the existence of an underlying common factor(s). The present study's KMO test yielded a statistic of 0.886 which suggests that items share a large proportion of variance and are suitable for factor analysis. ${ }^{6}$

After verifying that the data were suitable for factor analysis, this study then selected an appropriate extraction method to determine the number of underlying latent

\footnotetext{
${ }^{6}$ Bartlett's test of sphericity is another commonly used test to determine whether factor analysis is appropriate. However, this study did not conduct this test due to its sensitivity to samples that depart from multivariate normality.
} 
factors. EFA extraction methods are iterative processes that rely on matrix algebra to create linear combinations of items that explain the maximum amount of variance between items (Beavers et al., 2013). The first extraction in this process is based off the assumption that each linear combination is independent (Beavers et al., 2013). These linear combinations represent factors. This iterative process continues until all of the sample's variance is accounted for (Suhr, 2006).

The two most commonly used extraction methods for EFA include Maximum Likelihood (ML) and Principal Axis Factoring (PAF). The ML extraction method assumes that the data follow a multivariate normal distribution and that variables are continuous (Pett, Lackey \& Sullivan, 2003). For these reasons, ML was not an appropriate extraction method for this study's data. Unlike ML, PAF does not make strong assumptions about normality (Fabrigar et al., 1999). Consequently, it is less likely than ML to produce improper solutions. However, a downside of PAF is that it does not allow researchers to analyze confidence intervals or significance tests. It also only provides a restricted range of goodness-of-fit indexes. Despite these restrictions, this study selected PAF as an extraction method due to its relaxed assumption regarding normality.

Recall that factor analysis interprets inter-correlations between variables and with this knowledge identifies common factors. Consequently, the core of factor analysis can be said to be its correlation matrix. The Pearson correlation matrix is the default in most statistical software packages for factor analysis such as STATA. This study used a polychoric matrix to conduct its EFA because the Pearson correlation matrix requires that items are measured on an interval or ratio scales. Using a polychoric correlation matrix 
and PAF as an extraction method, this study applied EFA to its 12 fear of crime items. There are several criteria for identifying the appropriate number of latent factors. For EFA, these include identifying differences in eigenvalues, the cumulative percent of variance extracted by each factor and parallel analysis. It is highly recommended that multiple approaches are used to determine the number of appropriate factors.

Table 4 displays the eigenvalues and differences between eigenvalues for each factor. Eigenvalues represent the maximum amount of variance that has not been accounted for by previous factors (Suhr, 2006). They are produced by the PAF extraction method. Since PAF uses an iterative process to determine eigenvalues, the first factor's eigenvalue represents the greatest amount of variance among items. As seen in Table 4, some eigenvalues are negative. In essence, negative eigenvalues occur because the matrix used to calculate them is not of full rank meaning that the rows and columns of the matrix are not linearly independent. In other words, the corresponding factors of these negative eigenvalues do not explain any additional common variance among items that is not already accounted for by previous factors. Consequently, the calculations of these eigenvalues overlap with other eigenvalues. Some authors suggest that negative eigenvalues indicate multicollinearity and that redundant variables should be removed. However, multicollinearity is not a major problem in factor analysis since its goal is to consolidate redundant items into factors.

Insert Table 4 about here

High eigenvalues should be considered for retention because they represent factors that capture substantial proportions of variance (Maroof, 2012). Contrastingly, small eigenvalues do not capture adequate proportions of variance and likely reflect error 
or the influence of a few number of items. The Kaiser-criterion is a commonly used factor extraction method that states that factors that have eigenvalues greater than one should be retained. However, this criteria is highly debated and not appropriate for EFA because it is based on the assumption that factors that have eigenvalues of greater than one consist of items that are able to contribute one unit of variance (Beavers et al., 2013). Since EFA only considers common variance, the variance included for each item must be less than one (Beavers et al., 2013). In fact, the Kaiser criteria has been shown to overestimate the number of factors (Ruscio \& Roche, 2012).

Kaiser-criterion aside, eigenvalues and the proportion of the variance their corresponding factors explain are still useful to gain a rudimentary understanding of the number of factors that should be extracted. The difference between the first and second eigenvalues displayed in Table 4 suggests that this study only has one factor. A plot of the factors and their corresponding eigenvalues, known as a scree plot, better displays the dramatic difference between the first and second eigenvalues (see Figure 6). Generally, the factors that are most eligible for retention are the ones that appear before the steep drop. By this criteria, the scree plot also seems to suggest a one factor solution. In addition, the first factor alone explains a substantial proportion of the sample's variance: 77\%. Together, these findings mirror the earlier analysis of the polychoric correlation matrix which suggested a one factor solution. A one factor solution makes substantive and theoretical sense since all items included in this factor analysis have been used in research in some form to assess fear of crime.

Parallel analysis (PA) is yet another way to determine the number of factors for retention. PA generates random parallel datasets. The mean eigenvalues of each factor 
generated from these datasets are then compared to the sample's eigenvalues. It is suggested that the factors whose eigenvalues are greater than the eigenvalues generated randomly should be considered for retention (Maroof, 2012). A comparison of EFA and PA eigenvalues seems to suggest a 6 factor solution. However, the differences between many of these comparisons are substantively negligible. Setting aside these negligible differences, a one or two factor solution gains the most credibility. A one factor solution is appropriate because all the item loadings are considerably higher on the first factor than the second. ${ }^{7}$ Moreover, there is no logical substantive or theoretical reason to explain what the second factor represents.

Next, this study created factor scores from a one factor solution using a least squares regression approach. Each participant received a factor score that represented his or her standing on the latent concept of fear of crime. Factor scores ranged from a minimum of 1.2157 to a maximum of $8.5098 .^{8}$ These factor scores represent this study's fear of crime outcome. For simplicity, this study will refer to this outcome as a "fear of crime index." Scores at the higher end of this index represent a greater standing on the latent concept of fear of crime. Table 5 displays the descriptive statistics for the fear of

\footnotetext{
${ }^{7}$ This study makes the argument that the difference between the first factor's eigenvalues observed in the PA is more dramatic than all other eigenvalue differences. In addition, the items' factor loadings -which represent the correlation of an item with a factor- on the second factor are not nearly as strong as their loadings on the first factor. Depending on the criteria, many of the items could be considered cross-loaded between the first and second factor. To be considered cross-loaded, an item's factor loadings must be considered high on more than one factor. The criteria for "high" is subjective. Factor loadings as low as \pm 0.30 are often interpreted as high loadings (Costello \& Osborne, 2005). However, cross-loading only becomes an issue when more than two factors are eligible for retention. Consequently, cross-loading is not an issue for the present study and does not affect the calculations of factor scores attained from a one factor solution.

${ }^{8}$ The least squares regression approach to calculating factor scores does not produce factor scores that are standardized to a mean of zero as indicated by a positive minimum and maximum factor score. This is because this study conducts its EFA using a polychoric correlation matrix. Nonetheless, this study's approach still produces a continuous variable that is approximately normally distributed.
} 
crime index for the whole sample and for each level of the independent variable. This variable is approximately normally distributed and continuous.

Insert Table 5 about here

\section{Independent Variable}

As mentioned, this study used a computer program to adjust a photograph taken of a vacant lot to reflect a disorderly lot, a greened lot and a CPTED lot (i.e., the three levels of the study's independent variable). This study commissioned a graphic designer to make these adjustments. Prior to these adjustments, this study provided its graphic designer with instructions to create a template image. The goal of creating a template image was to develop a blank canvas from which prior adjustments could be easily made to simulate each level of the independent variable. The following items were removed from the original photograph to create this template: the telephone pole and telephone lines; the wooden, brick and metal fences; the cracks in the street pavement and sidewalk; the evergreen tree; and the cars parked in the street (see Figure 1 and Figure 2). After these adjustments were made, the graphic designer used this template to construct a disorderly, greened and CPTED lot.

To create a disorderly lot, this study instructed its graphic designer to adjust the template to include physical disorder. As previously defined, physical disorder includes physical elements of the environment that act as signals of neighborhood dilapidation (Skogan, 1990). Moreover, while constructing this disorderly environment the graphic designer was instructed to pay particular attention to creating environmental conditions that would limit the ability of non-offenders to see into the lot, allow offenders the opportunity to hide undetected and include barriers preventing victims from easily 
escaping the advances of potential offenders. These three qualities of the environment (i.e., blocked prospect, concealment and entrapment) are associated with high levels of fear of crime and are staple features of vacant lots (Day, 1994; Fisher, Sloan \& Wilkins, 1995; Nasar \& Fisher, 1992; Nasar \& Jones, 1997). In particular, the graphic designer added the following items to the template image to simulate a disorderly environment: overgrown grass, bushes and trees; a pile of tires; piles of cement; trash bags; an abandoned car; and miscellaneous debris (see Figure 3)

This study determined the requirements to create a greened lot by comparing the techniques used by major urban greening organizations across the country to transform vacant lots (Baltimore Greenspace, 2013; Greening of Detroit, 2014; Pennsylvania Horticultural Society, 2014; Urban Green Council, 2014). These requirements have been referred to as traditional urban greening practices and represent the most basic and commonly employed urban greening procedures. A unifying and foundational quality of all traditional urban greening practices is their transformation of vacant lots from disorderly to orderly conditions. In addition, low-maintenance plants, such as trees and grass, are planted in an effort to beautify the lot. In particular, trees are often planted in a systematic pattern. Many of these features, such as grass and no (physical) disorder, are already reflected in the template image. Consequently, the graphic designer was only required to include (young) trees arranged in some systematic fashion in the template image (see Figure 4).

This study used a two-pronged approach to develop the requirements to create a CPTED lot. First, an analysis of relevant literature revealed the most foundational and agreed upon standards of CPTED (Atlas, 2008; Bell, 1991, 1992; Brantingham \& 
Brantingham, 1981; Clarke \& Mayhew, 1980; Cozens, Saville \& Hillier, 2005; Crowe, 1991; Fennelly \& Crowe, 2013; Jeffery, 1971, 1977; Moffat, 1983; Newman, 1972;

Wallis \& Ford, 1981). As previously introduced, these standards include territoriality, surveillance, access control and maintenance. Next, this study investigated the ways in which these standards are commonly applied to the physical environment (Hedayati et al., 2012a, 2012b; Minnery \& Lim, 2005; Paranaby, 2007; Perkins et al., 1993; Sakip, Johari \& Salleh, 2012; Sutton, Cherney \& White, 2008). From this analysis, this study created a table of the underlying objectives of each CPTED standard and the most commonly used adjustments to the environment to achieve them (see Table 1). The graphic designer was instructed to add these adjustments to the template to simulate a CPTED lot (see Figure 5). Table 6 outlines the adjustments required to create the template image, a disorderly lot, a greened lot and a CPTED lot. This study provided its graphic designer with a copy of this table.

Insert Table 6 about here

As previously mentioned, each participant was randomly assigned one of the three images. Random assignment resulted in $\mathrm{N}=172$ participants assigned the disorderly lot image, $\mathrm{N}=172$ participants assigned the greened lot image and $\mathrm{N}=179$ participants assigned the CPTED lot image.

\section{Individual-level Factors}

The present study collected data on several previously discussed individual-level factors that are known to influence fear of crime. In addition to providing insight into the characteristics of the sample, this data makes it possible to directly test for equivalence among the three experimental conditions. 
Sex. Participants identified their sex as either male or female. This study measured sex as a binary variable that indicates whether participants identified as male or female $(0=$ female, $1=$ male $)$.

Race. Participants selected one racial or ethnic category that they identified with the most. Responses included "White," "Asian/Pacific Islander," "Black/African American," "American Indian or Alaskan Native" or "Some Other Race." This study created four binary variables using these categories: "White," "Asian/Pacific Islander," "Black/African American" and "Other Race." The "Other Race" variable includes participants who identified as either "American Indian or Alaskan Native" or as "Some Other Race.”

Hispanic. Participant's identified their ethnic origin as either Hispanic, Latino or Spanish or not Hispanic, Latino or Spanish. This study measured Hispanic, Latino or Spanish ethnic origin as a binary variable, "Hispanic" $(0=$ not of Hispanic, Latino or Spanish origin, 1= Hispanic, Latino or Spanish origin).

Age. Participants provided their age in years.

Hometown. Participant's selected the description that best represented their hometowns. This study defined hometown as the place where an individual spent the majority of his or her life. Responses included "Rural" (a small town or village in the country), "Urban" (a large central city) or "Suburban" (a smaller town within a metropolitan region but not the core city). To facilitate responses, this study provided examples of places that fit the definitions of each of these categories. This study created three binary variables from participants' responses: "Rural," "Urban" and "Suburban." 
Socioeconomic Status. Past research has commonly used receipt of a Federal Pell Grant as a proxy for students' socioeconomic status in lieu of more traditional measures, such as the income-brackets of students' parents/guardians, which are likely to be inaccurately reported (Heller, 2007). In light of this research, this study asked participants to indicate whether they have ever been the recipient of a Federal Pell Grant. Responses included either "Yes" or "No" ( $0=$ No, $1=$ Yes). To facilitate responses, this study also provided students with a formal definition of a Federal Pell Grant (a form of student financial aid awarded by the government and requires no repayment).

Direct Victimization Experience. Participants indicated every crime type that they had ever been a victim of within the last 12 months. These crime types included robbery, physical assault, harassment, sexual assault, motor vehicle theft, burglary and other (not listed) crime. This study also provided participants with definitions of each crime type which were adapted from the Uniform Crime Report (UCR) and from non-governmental sources. Furthermore, this study selected the reference period of the last 12 months based upon its use by multiple reputable sources to measure victimization experience (e.g., CS, GSS, Gallup Organization and NORC). Due to the scarcity of direct victimization experiences, this study measured direct victimization experience as the binary variable "Direct Victimization" which indicates whether participants were the victim of any of the previously identified crime types within the last 12 months $(0=$ no direct victimization experience, $1=$ direct victimization experience)

Indirect Victimization Experience. Participants indicated every crime type that a family member or friend had ever been a victim of in the last 12 months. To remain consistent, the same crime types and reference period that were used to measure direct 
victimization experiences were used to measure indirect victimization experiences. This study also provided participants definitions of each crime type. Similar to the direct victimization measure, indirect victimization experiences were scarce. For this reason, this study measured indirect victimization experience as the binary variable "Indirect Victimization" which indicates whether participants were aware of any friends or family members who had been the victims of any of the previously identified crime types within the last 12 months $(0=$ no indirect victimization experience, $1=$ indirect victimization experience)

Locus of Control. As previously discussed, it is prudent to identify participants' perceived loci of control when risk of victimization is included in the construction of a fear of crime measure. To identify one's locus of control, Rotter (1966) developed a 29item, forced-choice scale. Due to its length, Rotter's (1966) scale is not often implemented when time is at a premium, such as in the case of distributing questionnaires in a classroom setting. Because of its impracticality in a timed setting, many scholars have sought to validate an abbreviated version of Rotter's (1966) scale. Lumpkin (1985) is one such scholar.

Lumpkin (1985) identified six items from Rotter's (1966) scale. To rate these items, Lumpkin (1985) used a five-point Likert scale ranging from "strongly disagree" to “strongly agree" (see Table 7). ${ }^{9}$ The Cronbach's alpha coefficient for Lumpkin's (1985) scale is .68, making it comparable to coefficients reported by scales developed by Rotter (1966) and other scholars (Bugaighis \& Schumm, 1983). Moreover, to establish validity, Lumpkin conducted correlations between scores on the abbreviated version of the locus

\footnotetext{
${ }^{9}$ Lumpkin (1985) only indicates what the extreme levels (1 and 5) of the 5-point Likert scale signify. Consequently, this present questionnaire does not provide a description for the remaining levels.
} 
of control scale with several other constructs which have been shown to be related to locus of control through prior research. Among these constructs, Lumpkin (1985) found a negative correlation between internal locus of control and perceived risk, mirroring the findings of past research (Rudnick \& Deni, 1980).

Insert Table 7 about here

In light of these demonstrations of internal consistency and validity, Lumpkin's (1985) abbreviated locus of control scale appears to be a worthy substitute for Rotter's (1966) lengthier locus of control scale. For this reason, this study used Lumkpkin's (1985) abbreviated locus of control scale. Participants' responses were reverse-coded so that larger scores on the five-point scale indicated a more internal locus of control. Participants' scores were then summed and recorded as counts. This study used these counts to create the binary variable "Internal" which indicated whether participants had internal or external loci of control $(0=$ external locus of control, $1=$ internal locus of control). To create this measure, this study used the cutoff of score of 17 , the mean and median of the distribution. This cutoff was selected to remain consistent with past measurements of this variable (Caliendo, Cobb-Clark \& Uhlendorf, 2010). Participants whose total summed scores were greater than 17 were classified as having internal loci of control whereas all other participants were classified as having external loci of control.

Table 8 displays the descriptive statistics of the individual-level factors for the whole sample and for each level of the independent variable. Overall, respondents are, on average, female (52\%), white (64\%), non-Hispanic (87\%), 20 years of age, from the suburbs (75\%) and not the recipients of Federal Pell-Grants (74\%). In addition, participants have, on average, external loci of control (52\%) and never been victims, or 
have friends or family members who have been victims, of any of the identified crime types within the last 12 months (75\% and 63\%, respectively). ${ }^{10}$

Insert Table 8 about here

This study will use these individual-level factors to evaluate equivalence across the three levels of the independent variable. In essence, the purpose of evaluating equivalence is to assess whether the differences between two or more groups on some outcome are small enough to be considered negligible or similar (Rusticus \& Lovato, 2011). Random assignment dictates that individual-level factors should be approximately equally distributed across groups. Assessing equivalence helps determine the extent to which this is true.

This study will use a two-proportion z-test for binary outcomes and a two-sample t-test from the continuous outcome age to assess equivalence across the three levels of the independent variable. The two-proportion z-test tests the null hypothesis that there is no statistically significant difference between two population proportions. Alternatively, the two-sample t-test tests the null hypothesis that there is no statistically significant difference between two population means. These tests must be conducted multiple times for equivalence testing involving more than two groups. The present study will compare differences in proportions/means between the greened and disorder lot conditions, the CPTED and greened lot conditions, and the CPTED and disorder lot conditions for each

\footnotetext{
10 Demographic statistics on the undergraduate student body were obtained from the large East Coast university from which this study's sample was drawn. The undergraduate student body is predominantly male $(52.97 \%), 20$ to 21 years of age, white (55.3\%) and non-Hispanic $(92.1 \%)$. Furthermore, $12.1 \%$ of the undergraduate student body identified as Black or African American and 14.9\% as Asian. With the exception of sex, there are some substantive similarities between the demographic characteristics of the undergraduate student body and the sample of students who participated in this study.
} 
individual-level factor, totaling 42 comparisons. A benefit of this approach is that it offers a more comprehensive account of the nature of the differences across groups. 


\section{Chapter 4: Results}

Using the individual-level factor variables, this study first checked for balance across the three levels of the independent variable using a two-proportion z-test for binary outcomes and a t-test for the continuous outcome Age. Table 9 displays the results of these tests. This study used a cut-off value of $p<0.05$ to identify statistically significant differences in proportions and means. Of these comparisons, the only statistically significant differences across levels was whether participants were the recipients of a Federal Pell Grant and whether they had been victimized in the last 12 months. More specifically, Federal Pell Grant recipients were more likely to have been assigned a greened or CPTED lot than a disorderly lot. Furthermore, participants who had been victimized in the last 12 months were more likely to have been assigned a CPTED lot than a disorderly lot. Due to their imbalance across the levels of the independent variable, both the Federal Pell Grant and Direct Victimization measures were included in subsequent OLS regression models as controls. ${ }^{11}$

\section{Insert Table 9 about here}

This study conducted OLS regression models to test its hypotheses. This study tested its first hypothesis by analyzing the slope coefficients of the Greened and CPTED dummy variables against the Disorder reference category. To test its second hypothesis, this study used a post-estimation t-test to compare participants' relative standings on the latent concept of fear of crime who viewed a CPTED lot to those who viewed a greened

\footnotetext{
${ }^{11}$ It may be the case that this imbalance is the result of random chance due to the number of tests that were run and do not identify real differences across the three levels of the independent variable. To account for this possibility, Table 11 depicts the OLS regression model without the controls Federal Pell Grant and Direct Victimization. The results of this model are substantively similar to the results of the model in which these measures were included as controls.
} 
lot. Here, the Greened and CPTED dummy variables are compared relative to the Disorder reference category. This comparison reflects the fact that disorderly vacant lots are the starting place of many urban-greening interventions. To reflect this reality, this study is concerned with potential reductions in fear of crime that occur from the transformation of disorderly vacant lots into CPTED lots over greened lots and not from the transformation of greened lots into CPTED lots. ${ }^{12}$

Table 10 displays the OLS regression results. ${ }^{13}$ Holding all else constant, participants who viewed either a greened or CPTED lot had significantly lower standings on the latent concept of fear of crime than participants who viewed a disorderly lot. In particular, participants who viewed a CPTED lot scored, on average, 1.6164 points lower on the fear of crime index than participants who viewed a disorderly lot, whereas participants who viewed a greened lot scored, on average, 1.2933 points lower. This finding is consistent with this study's first hypothesis.

Insert Table 10 about here

Furthermore, a post-estimation t-test identified a statistically significant difference in participants' standings on the latent concept of fear of crime between those who viewed a greened lot and those who viewed a CPTED lot. The magnitude and the sign of the slopes of these two variables suggest that, on average, participants who viewed a

\footnotetext{
${ }^{12}$ For the reason previously described, this study is not interested in the direct comparison of CPTED and greened lots. Nonetheless, this study conducted a separate analysis in which disorderly lot cases were dropped so that CPTED lots could be directly compared to greened lots, the reference category, using OLS regression $(\beta=-0.31313, \mathrm{p}=0.053)$. Both the Federal Pell Grant and Direct Victimization measures were included in this model as controls.

${ }^{13}$ This study also tested its hypotheses using factor scores produced using a Pearson correlation matrix. The results of these hypothesis tests were substantively similar to those found using factor scores produced from a polychoric correlation matrix.
} 
CPTED lot had lower standings on the latent concept of fear of crime than participants who viewed a greened lot. This finding lends support to this study's second hypothesis. 


\section{Chapter 5: Discussion \& Conclusion}

The present study is the first of its kind to assess the effect of incorporating CPTED standards into traditional urban greening practices of vacant lots on fear of crime. Supporting its first hypothesis, this study found that the traditional and CPTED approaches to greening vacant lots were associated with lower levels of fear of crime compared to an untransformed, disorderly vacant lot. This finding is not surprising given past research on the effects of environmental features, most notably physical disorder, on fear of crime. Moreover, this finding suggests that traditional urban greening practices and the CPTED adjustment are both viable options to reduce fear of crime. More interestingly, this study found that incorporating CPTED into traditional urban greening practices was associated with lower levels of fear of crime than the traditional approach. This comparison was made relative to a disorderly vacant lot in order to reflect the reality of when CPTED would be implemented in the greening process. This finding, which supports this study's primary hypothesis, suggests that incorporating CPTED standards into traditional urban greening practices may help optimize reductions in fear of crime in neighborhoods.

The reduction in fear of crime achieved by incorporating CPTED standards into traditional urban greening practices may have additional related benefits for communities. For example, if individuals feel safer they will be more likely to use public spaces and engage with other community members (Pitner, Yu \& Brown, 2012). These activities facilitate collective efficacy and informal social control which make neighborhoods safer (and more desirable) places to live (Gibson et al., 2006). In particular, research has shown that neighborhoods with high levels of collective efficacy 
and informal social control are more intolerant to crime and more active to abate it (Gibson et al., 2002; Silver \& Miller, 2004).

This study has several theoretical and policy implications. This study's construction of its fear of crime measure contributes to a major theoretical debate underlying fear of crime research. This debate involves how to define and subsequently measure fear of crime. In particular, this study found that perceptions of safety, risk of victimization and fear of victimization all measure the same underlying latent concept. In other words, this study did not find evidence to suggest that these fear of crime elements are conceptually distinct and that using one fear of crime measure over another provides added value in regards to capturing one's level of fear of crime. This finding supports past research which questions fear of crime's multi-dimensional character and the unique contributions of its cognitive and affective elements advocated by some scholars (Ferraro \& LaGrange, 1987; Marzbali et al., 2012).

This study's findings also have theoretical import in regards to CPTED's ability to impact fear of crime. Recall that CPTED relies on its ability to influence individuals' perceptions of the environment which in turn inform their levels of fear of crime. This study's findings suggest that CPTED is able to influence individuals' perceptions of the environment that impact their levels of fear of crime in artificial (or computer-generated) environments. More generally, individuals are able to identify and interpret cues present in artificial environments that affect their fear of crime responses. This study's findings support the use of artificial environments to identify the impact of CPTED on fear of crime as well as to investigate the underlying mechanisms by which this relationship operates. 
Furthermore, this study is able to provide some direction for future policy regarding urban greening despite the restricted generalizability of its findings. Insofar as fear of crime is linked to a host of negative outcomes that debilitate communities, this study's findings suggest that city officials need to more deliberately consider what can be done to optimize reductions in fear of crime in the transformation of vacant lots. To this point, city officials should investigate whether incorporating CPTED standards into traditional urban greening practices is a worthwhile endeavor to pursue in order to optimize reductions in fear of crime in their communities. City officials should conduct some preliminary investigations on this topic that are low-cost and easy to implement before action is taken to incorporate CPTED standards into the greening process. ${ }^{14}$

For example, one low-cost, easy way in which city officials could assess the impact of incorporating CPTED into the greening process in regards to fear of crime is to host discussions on this topic with community members at community centers. To facilitate discussion, city officials could present images of vacant lots that have been greened according to traditional and CPTED practices. This approach would allow city officials to gain a nuanced understanding of fear of crime in communities and insight into whether incorporating CPTED standards into traditional greening practices would provide added benefits, such as increases in quality of life, beyond the traditional endeavor. From here, city officials could decide whether it is worthwhile to develop

\footnotetext{
${ }^{14}$ It is important to point out that what is considered to be a low-cost, easy evaluation likely varies across communities; what may be a low-cost evaluation for one community may be an expensive evaluation for another. In general, communities in which vacant lots are the most pervasive have limited financial resources. In such places, it is not feasible to invest a substantial amount of money in preliminary investigations to assess whether incorporating CPTED into traditional urban greening practices is a worthwhile endeavor to pursue. In the discussion that follows, this study focuses on what low-cost, easy evaluations may resemble for communities with the most restricted budgets.
} 
more costly and complex methods to evaluate whether incorporating CPTED standards into the greening process optimizes reductions in fear of crime over traditional practices. In particular, it is important that city officials consider the financial and social costs and benefits of one greening approach over another. The simplistic methods of the traditional urban greening approach likely means that it will be less financially costly to implement and maintain than the more intricate CPTED adjustment. However, the higher financial cost of greening vacant lots according to CPTED standards and maintaining these lots may produce greater social and financial benefits related to optimizing reductions in fear of crime over the less costly traditional greening alternative. These social and financial benefits may include greater improvements in quality of life and decreases in crime and the cost of crime in communities. ${ }^{15}$ Less-costly evaluations, such as the one previously described, are able to provide some insight into the extent of these benefits. However, more costly and statistically rigorous community evaluations on this topic are needed in order to gain a more comprehensive understanding of the nature and type of benefits that can be achieved by incorporating CPTED into traditional greening practices. $^{16}$

\footnotetext{
${ }^{15}$ Cost of crime research evaluates several direct and indirect economic consequences of crime related to, for example, criminal justice system costs, victim costs and intangible costs. Direct consequences of crime may include the cost of neighborhood policing and property damage/loss. Indirect consequences, which are more difficult to measure in dollars, may include costs associated with victims' residual pain from a criminal event and their loss of quality of life (Miller, Cohen \& Wiersema, 1996).

${ }^{16}$ What may be a high-cost evaluation to one community may be a low-cost evaluation to another. For example, mail surveys are typically considered a low-cost evaluation strategy. However, they may be beyond the reach of some city officials to implement. For those that have the financial means to do so, city officials could organize mail surveys to be distributed- that resemble those of the present study- to a random sample of households. This approach would allow city officials to identify a treatment effect of greening vacant lots incorporating CPTED standards on fear of crime over traditional practices. Furthermore, city officials could also implement a pre-posttest quasi-experimental design in which they select segments of a community to transform vacant lots by traditional greening practices or by the CPTED adjustment. They could then compare the levels of fear of crime and crime as well as perceptions of quality of life around these lots before and after these interventions. This more costly and time consuming approach would allow city officials to better understand the related benefits of optimizing reductions of fear
} 
This study offers several directions for future research. First, future research should attempt to dissect the effect of each CPTED standard on fear of crime. As previously explained, the interconnectedness of CPTED standards makes it very difficult to separately distinguish their effects on fear of crime. Consequently, the present study evaluates CPTED as a package. However, it may be the case that only some standards are necessary to reduce fear of crime and that implementing CPTED as a package is not a very cost efficient option for greening vacant lots. To speak to this point, communities in which vacant lots are the most prevalent often have limited budgets devoted to transforming vacant lots through urban greening. In these communities, greening practices that are able to optimize reductions in fear of crime are arguably needed the most. For this reason, it would be helpful to evaluate the effect of each CPTED standard on fear of crime in order to determine whether this greening method can be made more affordable for communities that need it the most.

Second, future research should investigate the mechanisms underlying this study's treatment effect. This study did not attempt to understand how disorderly, greened and CPTED lots affected participants' fear of crime responses. Rather, like most experiments, it sought to identify a causal treatment effect. Open-ended survey questions and qualitative interviews both allow researchers to identify underlying mechanisms. In doing so, these techniques may provide some leverage over conducting evaluations of the effect of each CPTED standard on fear of crime. For example, researchers could add an openended question to this study's questionnaires that asks participants to describe what it is about a particular lot that makes them more or less afraid of falling victim to a crime. The

of crime and whether it is worthwhile to incorporate CPTED standards into traditional greening practices on a larger scale. 
results from this open-ended question could be compared to what is known about the connection between the physical environment and fear of crime from theory. However, it should be noted that open-ended survey questions will increase the amount of time subjects need to complete questionnaires. For this reason, open-ended survey questions may be especially problematic when surveys are administered in classroom settings where time is limited. Participants are also more likely to skip open-ended questions due to the effort needed to complete them (Fowler, 2014). When participants do respond, their response may range from very detailed to of minimal use (Fowler, 2014).

Researchers could also conduct in-person qualitative interviews to gain insight into underlying mechanisms. For example, researchers could show participants all three lot conditions and ask them to compare the images and rate how safe they would feel at each and why. Researchers will need to devout a considerable amount of time and resources to implement this approach. However, a major benefit is that they will be able to gain a deeper, more descriptive understanding of what it is about each lot that affects participants' levels of fear of crime. In doing so, researchers are more likely to develop a more comprehensive understanding of the underlying mechanisms influencing participants' levels of fear of crime which they can compare to relevant theory.

Third, there are several other types of evaluations that future research should conduct to better understand the effect of disorderly, greened and CPTED lots on fear of crime. In particular, research shows that fear of crime is higher at night than during the day (Nasar \& Jones, 1997). This study’s findings are specific to daytime conditions. It remains to be seen whether the gains in fear of crime reduction achieved by CPTED over traditional practices hold for nighttime conditions. Furthermore, future research should 
also investigate demographic differences in fear of crime across disorderly, greened and CPTED lots. Investigating these differences will help researchers gain a more nuanced understanding of fear of crime and, in particular, which groups of individuals benefit the most-in regards to reductions in fear of crime-from a particular greening approach.

Last, this study's findings suggest that it is worthwhile to purse a large-scale investigation of the effect of incorporating CPTED into traditional urban greening practices on fear of crime that utilizes more sophisticated computer software to create lot conditions and a sampling technique that captures participants that are representative of a future undetermined target population. As previously described, there are several more sophisticated alternatives to computer generated images, such as virtual environments and panoramic imaging, which were beyond the scope and means of this study. Future research should investigate these alternatives in light of their contributions to ecological validity. In addition, this study's student sample, although appropriate for its research purpose, greatly restricts the generalizability of its findings. To achieve greater external validity, future research should adopt sampling techniques that are better able to capture representative estimates of a population. Ideally, these sampling techniques should focus on capturing those individuals who are most likely to be exposed to disorderly vacant lot conditions in their communities.

It may also be worthwhile for researchers to study the effect of traditional and CPTED greening approaches on fear of crime using a sample of individuals who are not residents of the neighborhoods under evaluation but who frequent these neighborhoods for commercial purposes or who are prospective homeowners. Communities that contain disorderly vacant lots lack the vibrancy needed to attract outsiders to invest in their 
welfare. To elaborate, environmental cues associated with vacant lots (e.g., trash, graffiti and over grown vegetation) promote fear of crime and dissuade outsiders from frequenting local businesses and purchasing homes in these communities. Lack of support from outsiders can severely stifle local economies. In order to help revitalize communities, it is not only important to consider the impact traditional and CPTED greening approaches have on residents' fear of crime, but also the impact they have on the fear of crime of those outsiders who can help transform local economies.

In conclusion, this study has provided a starting place from which future research can begin investigating the impact of greening vacant lots incorporating CPTED standards on fear of crime. This study has demonstrated that greening vacant lots incorporating CPTED standards is capable of reducing fear of crime beyond traditional practices. Greening incorporating CPTED standards not only may optimize reductions in fear of crime in (blighted) communities but may also lead to substantial improvements in other outcomes affected by fear of crime, such as quality of life, beyond that which could be achieved by traditional greening practices alone. Future research should heed this study's recommendations for developing this research area. 
Appendix A

Introduction Script

Hello, my name is Alaina De Biasi. I am a graduate student in Criminology and I am conducting a study for my thesis on the impact of the environment on fear of crime. I would greatly appreciate your help by completing a questionnaire. You must be at least 18 years of age to participate in this study. Also, if you have already completed this questionnaire you cannot participate in this study a second time. I am now going to distribute questionnaires along with consent forms. Please do not do anything with these documents until I tell you to.

The questionnaire is nine-pages in length and should take approximately 10 to 15 minutes to complete. The first section asks you to report some demographic information such as your age and sex. It also asks if you or your friends or family members have been a victim of any of the following crime types: robbery, physical assault, harassment, sexual assault, motor vehicle theft, burglary or some other crime. The questionnaire provides definitions of these crime types. The second section provides you with a picture that you will use as a reference to answer questions related to fear of crime. Finally, the last section asks you to consider the extent to which you personally agree or disagree with a series of statements.

Please read the consent form first. You can keep the consent form for your records. After reading the consent form, if you choose to participate in this study please complete the questionnaire. In order to protect your privacy, do not sign your name on the questionnaire. By not signing your name on the questionnaire your responses will remain completely anonymous.

Please raise your hand when you would like to turn in your questionnaire and someone will come collect it from you. If you choose not to participate in this study, you must still turn in your questionnaire. Once you have turned in your questionnaire, please wait patiently while other students complete their questionnaires. After 15 minutes have elapsed, I must collect all remaining questionnaires.

Please feel free to contact me if you have any questions regarding this study or would like to receive a summary of its results. My contact information is included on the consent form. You may now begin reviewing the consent form and if you so choose move forward with completing the questionnaire. 


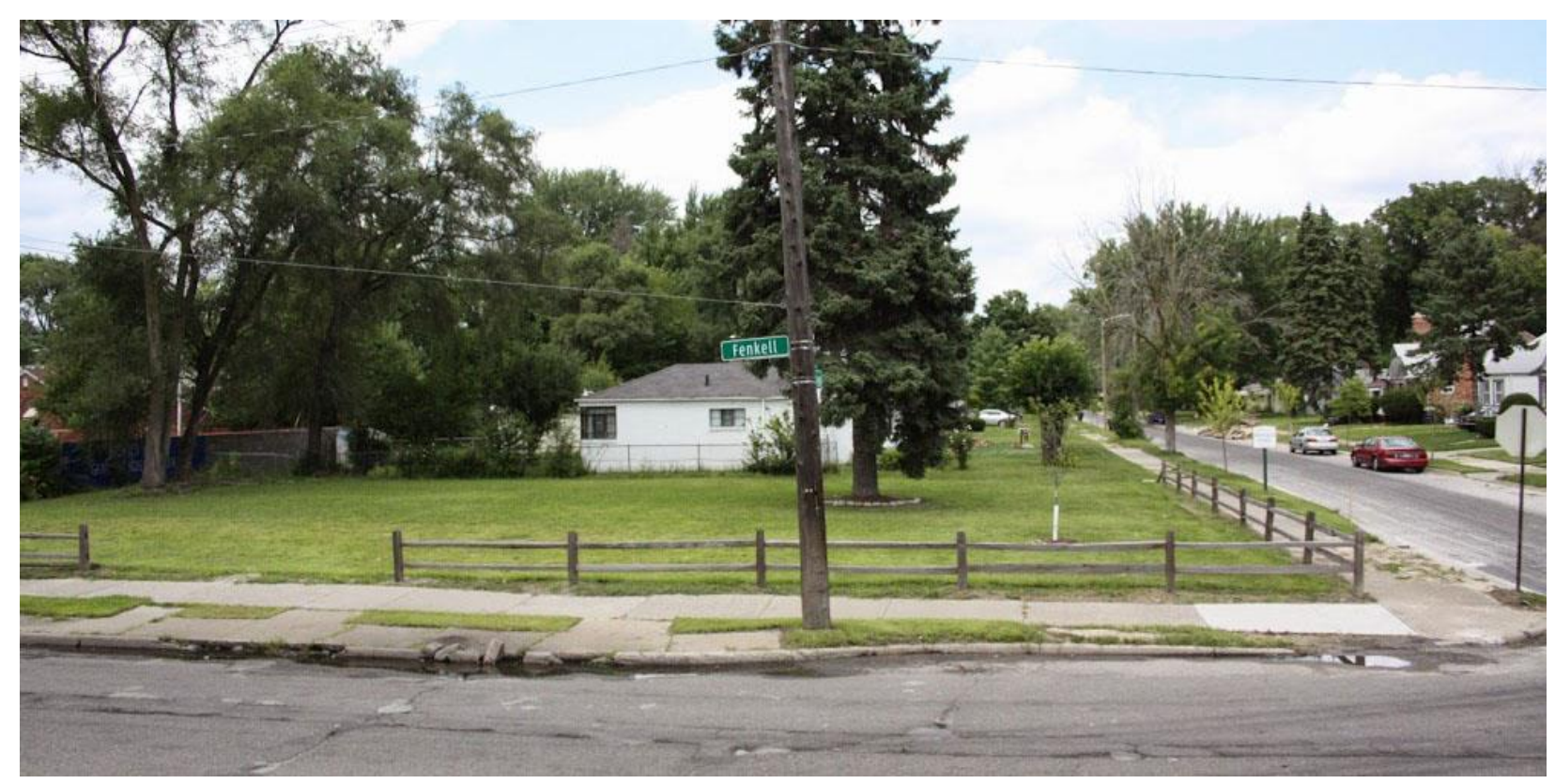

Figure 1. Original image of the vacant lot

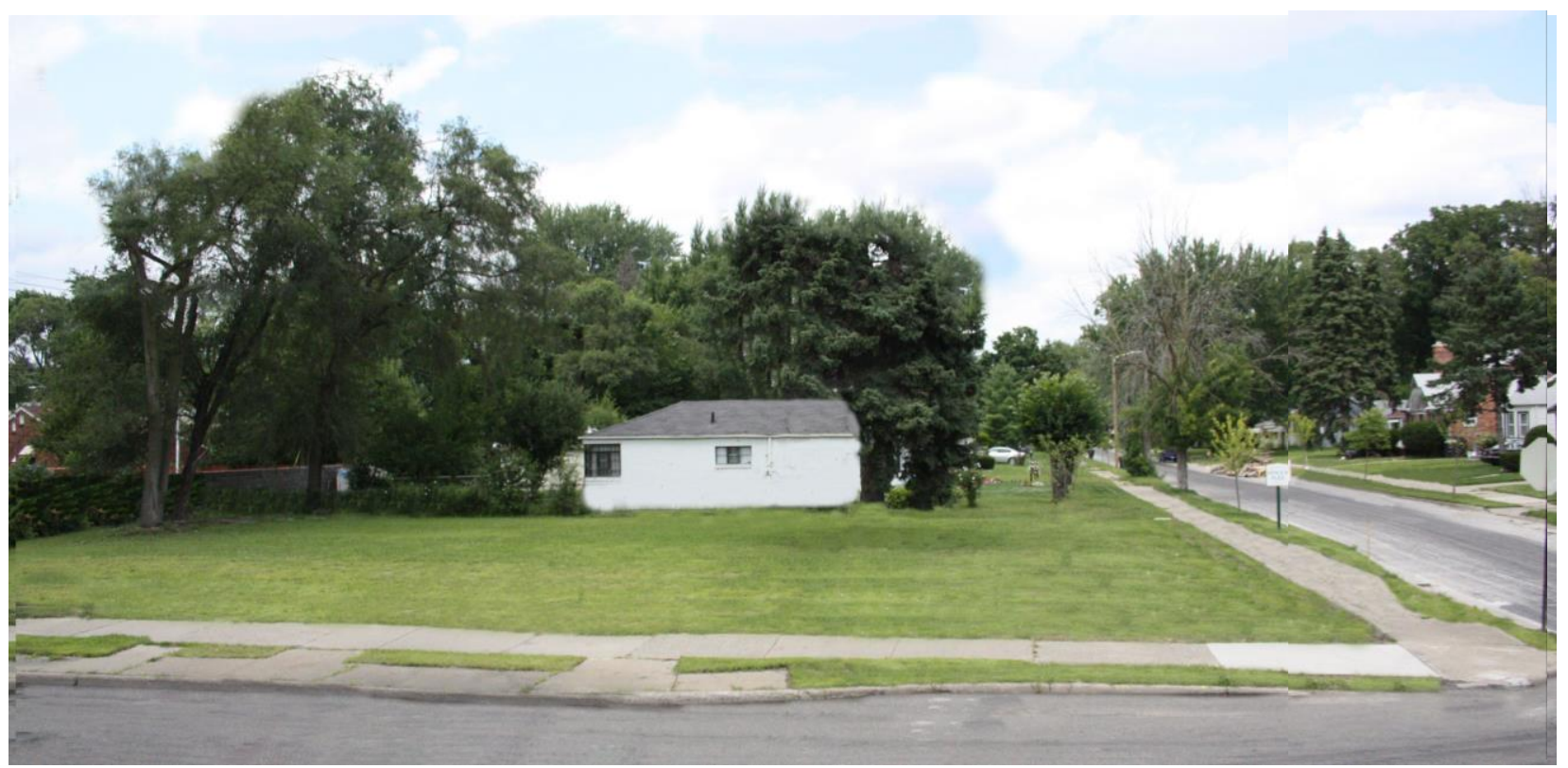

Figure 2. Template image 


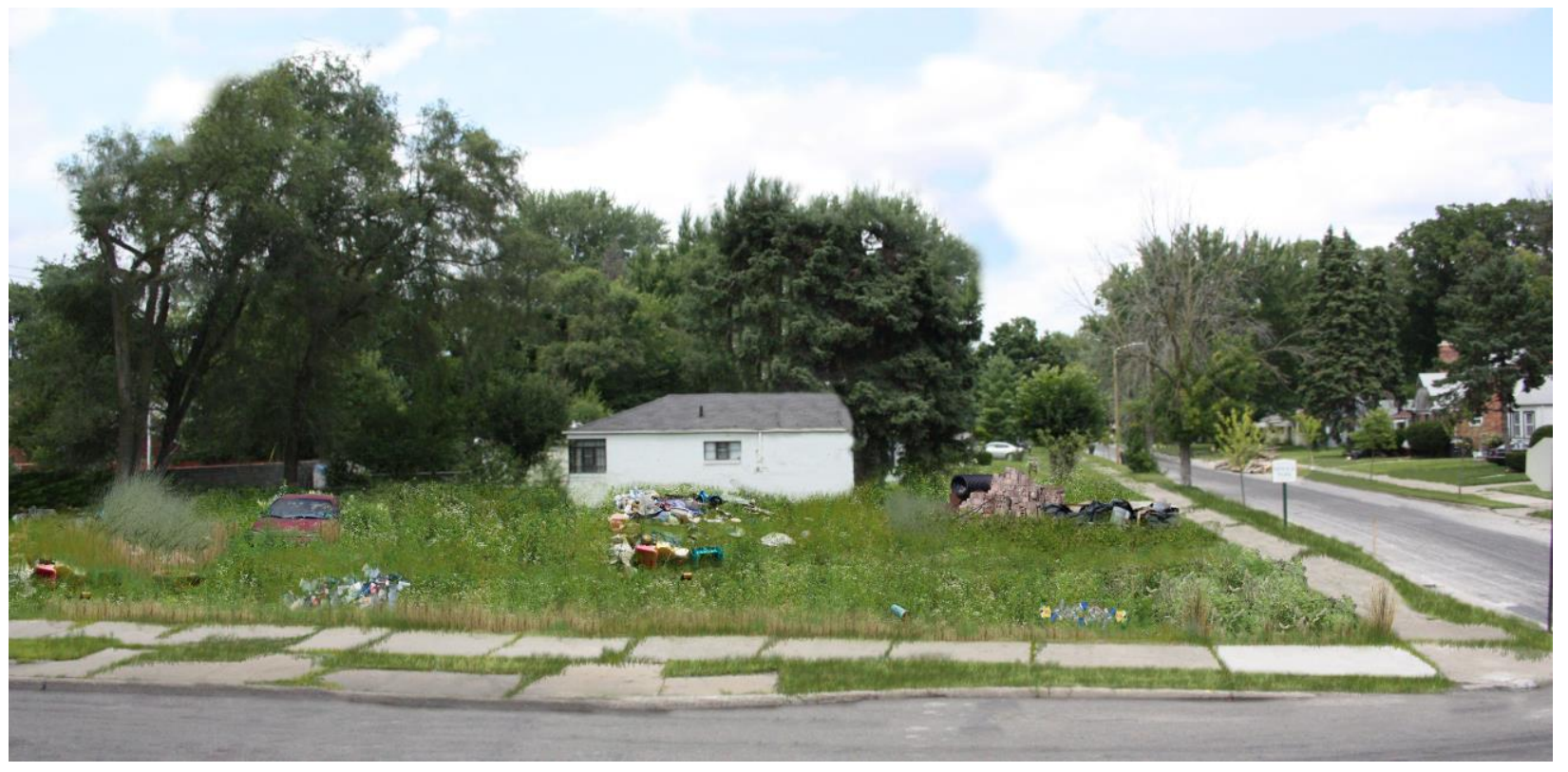

Figure 3. Disorderly lot

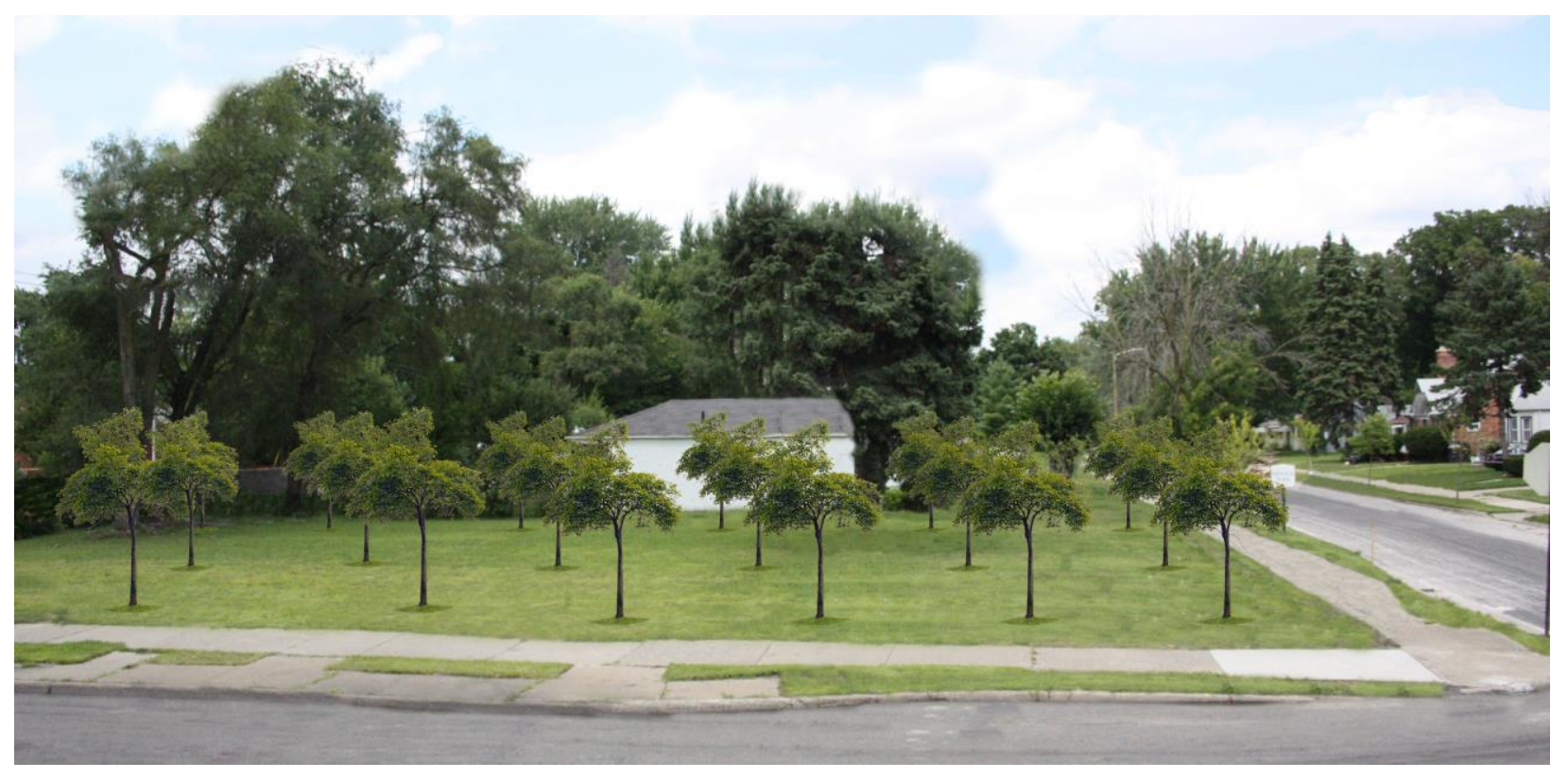

Figure 4. Greened lot 


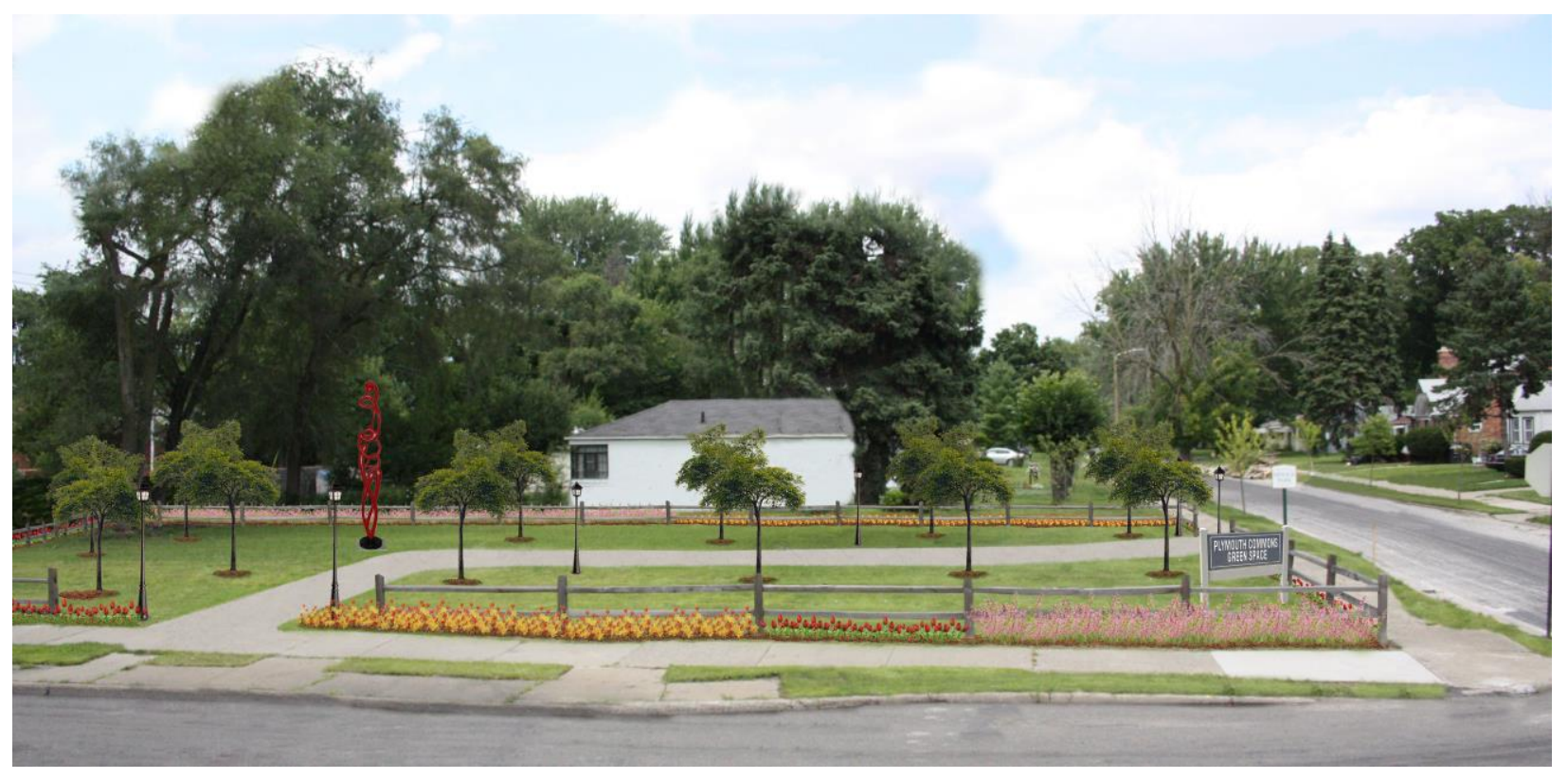

Figure 5. CPTED Lot

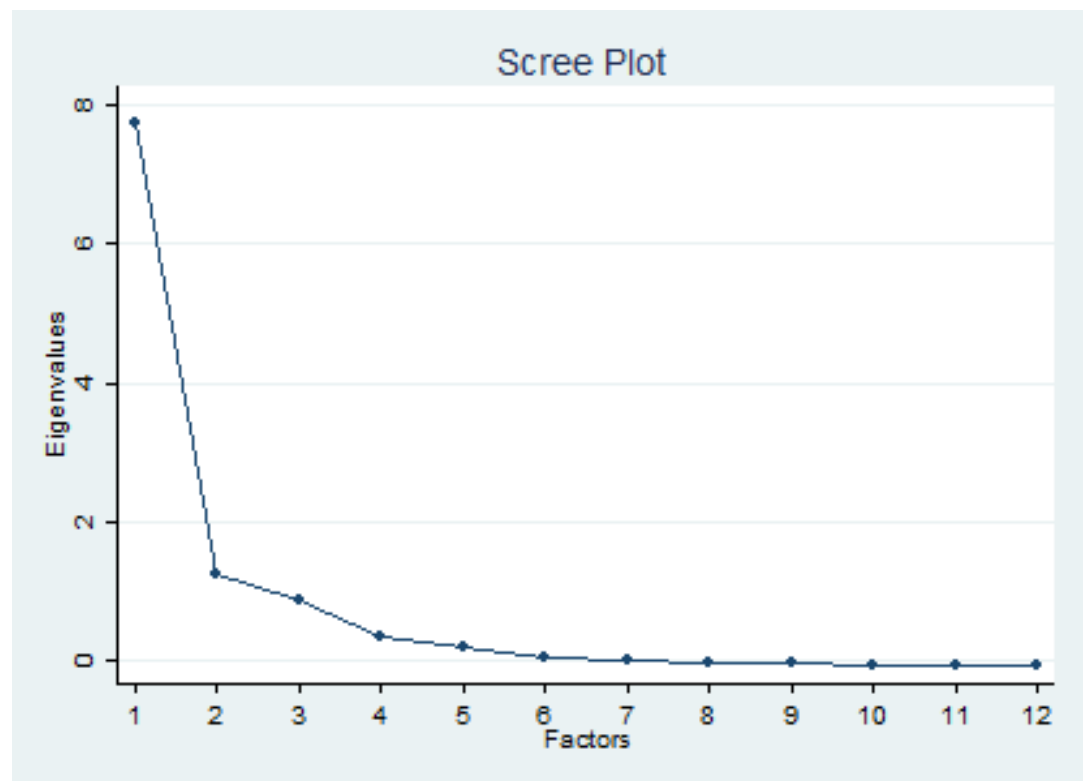

Figure 6. Scree Plot 
Table 1.

\begin{tabular}{|c|c|c|c|c|}
\hline & Territoriality & Surveillance & Access Control & Maintenance \\
\hline Objective & $\begin{array}{l}\text { Aims to promote a } \\
\text { sense of ownership } \\
\text { and facilitate } \\
\text { proprietary } \\
\text { concern }\end{array}$ & $\begin{array}{l}\text { Promotes an } \\
\text { individual's ability } \\
\text { to have clear views } \\
\text { of his or her } \\
\text { surroundings }\end{array}$ & $\begin{array}{l}\text { Involves constructing } \\
\text { a design that manages } \\
\text { the safe usage and } \\
\text { movement of } \\
\text { individuals into and } \\
\text { out of a space, with a } \\
\text { focus on decreasing } \\
\text { opportunities for } \\
\text { illegitimate use }\end{array}$ & $\begin{array}{l}\text { Refers to all } \\
\text { efforts required } \\
\text { to uphold a tidy } \\
\text { and orderly } \\
\text { appearance of a } \\
\text { space }\end{array}$ \\
\hline Adjustments & $\begin{array}{ll}\text { - } & \text { Fencing } \\
\text { - } & \text { Signage } \\
\text { - } & \text { Artwork } \\
\text { - } & \text { Flowers \& low } \\
& \text { lying bushes }\end{array}$ & - Lighting & $\begin{array}{l}\text { - Clearly defined } \\
\text { entrance and exist } \\
\text { - Defined route } \\
\text { - Fencing }\end{array}$ & $\begin{array}{l}\text { - } \begin{array}{l}\text { Removal of } \\
\text { debris }\end{array} \\
\text { - } \begin{array}{l}\text { Groomed } \\
\text { foliage }\end{array}\end{array}$ \\
\hline
\end{tabular}

Table 2.

Fear of Crime Descriptive Statistics

\begin{tabular}{|c|c|c|c|c|c|c|c|c|}
\hline \multirow[b]{2}{*}{ Variable } & \multicolumn{2}{|c|}{$\begin{array}{c}\text { Full Sample } \\
\qquad N=523\end{array}$} & \multicolumn{2}{|c|}{$\begin{array}{c}\text { Disorder } \\
\mathrm{N}=172\end{array}$} & \multicolumn{2}{|c|}{$\begin{array}{c}\text { Greened } \\
\mathrm{N}=172\end{array}$} & \multicolumn{2}{|c|}{$\begin{array}{l}\text { CPTED } \\
\mathrm{N}=179\end{array}$} \\
\hline & $\bar{X}$ & $\mathrm{SD}$ & $\bar{X}$ & SD & $\bar{X}$ & SD & $\bar{X}$ & SD \\
\hline \multicolumn{9}{|l|}{ Safety } \\
\hline Robbery & 4.2906 & 1.6341 & 5.2326 & 1.2582 & 3.9651 & 1.4981 & 3.6983 & 1.6855 \\
\hline Physical Assault & 4.3098 & 1.7896 & 5.2209 & 1.3456 & 3.9942 & 1.7219 & 3.7374 & 1.8912 \\
\hline Harassment & 4.2753 & 1.6332 & 5.1221 & 1.3901 & 3.9884 & 1.5967 & 3.7374 & 1.5663 \\
\hline Sexual Assault & 4.3881 & 1.9963 & 5.0698 & 1.7888 & 4.1802 & 1.9845 & 3.9330 & 2.0323 \\
\hline \multicolumn{9}{|l|}{ Afraid } \\
\hline Robbery & 3.8757 & 1.6786 & 4.7209 & 1.4481 & 3.6395 & 1.5553 & 3.2905 & 1.6842 \\
\hline Physical Assault & 3.8872 & 1.7378 & 4.6802 & 1.4896 & 3.6047 & 1.6134 & 3.3966 & 1.8157 \\
\hline Harassment & 3.7400 & 1.6966 & 4.5698 & 1.6511 & 3.4128 & 1.5962 & 3.2570 & 1.5401 \\
\hline Sexual Assault & 3.8987 & 1.9405 & 4.6047 & 1.8275 & 3.6512 & 1.8904 & 3.4581 & 1.9145 \\
\hline \multicolumn{9}{|l|}{ Likely } \\
\hline Robbery & 3.5679 & 1.5139 & 4.3547 & 1.4170 & 3.4302 & 1.3937 & 2.9441 & 1.3850 \\
\hline Physical Assault & 3.3270 & 1.4418 & 4.1512 & 1.4430 & 3.1163 & 1.2970 & 2.7374 & 1.1961 \\
\hline Harassment & 3.6176 & 1.4981 & 4.3372 & 1.5530 & 3.3430 & 1.3610 & 3.1899 & 1.3144 \\
\hline Sexual Assault & 3.2027 & 1.5662 & 3.9360 & 1.6898 & 3.0465 & 1.4421 & 2.6480 & 1.2650 \\
\hline
\end{tabular}


Table 3.

Polychoric Correlation Matrix

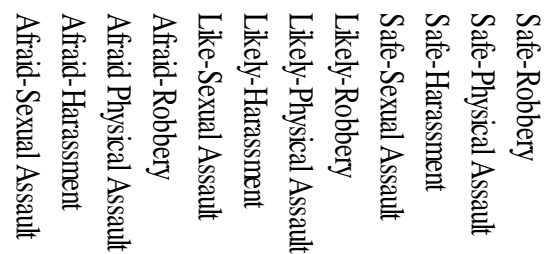

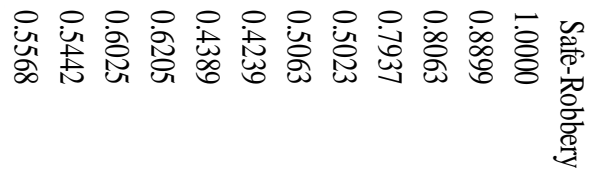

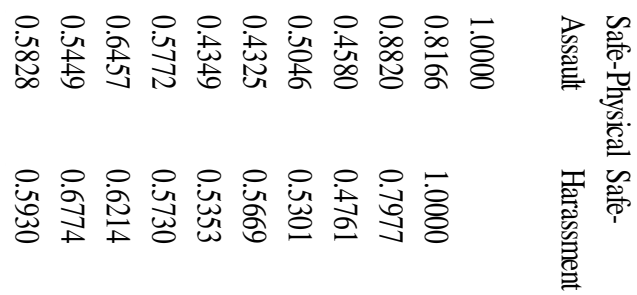

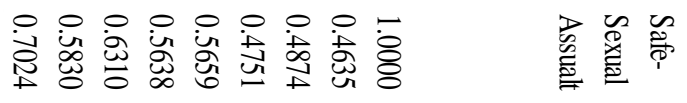

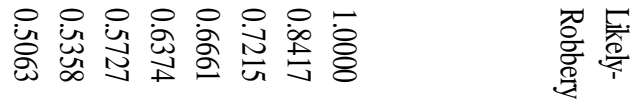

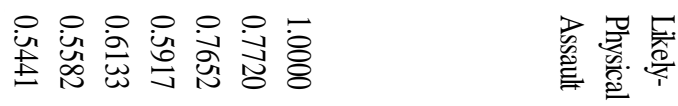

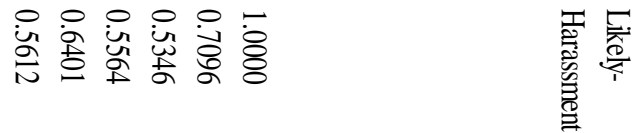

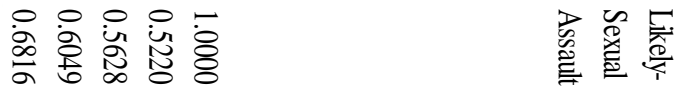

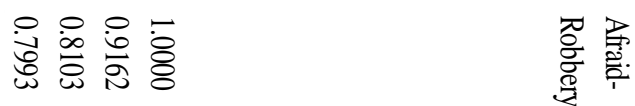

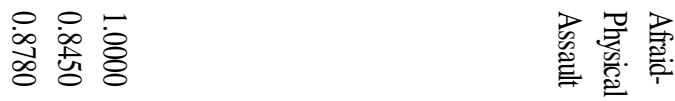

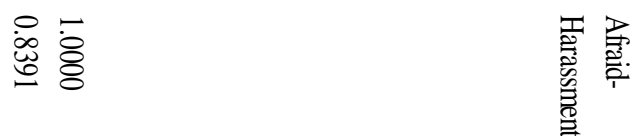

- 
Table 4.

Eigenvalues

\begin{tabular}{lll}
\hline Factor & Eigenvalue & Difference \\
\hline Factor 1 & 7.7332 & \\
Factor 2 & 1.2599 & 6.4733 \\
Factor 3 & 0.8569 & 0.4030 \\
Factor 4 & 0.3537 & 0.5033 \\
Factor 5 & 0.1889 & 0.1648 \\
Factor 6 & 0.0442 & 0.1447 \\
Factor 7 & 0.0123 & 0.0319 \\
Factor 8 & -0.0272 & 0.0395 \\
Factor 9 & -0.0515 & 0.0243 \\
Factor 10 & -0.0649 & 0.0134 \\
Factor 11 & -0.0768 & 0.0119 \\
Factor 12 & -0.0787 & 0.0018
\end{tabular}

Table 5.

Fear of Crime Index Descriptive Statistics

\begin{tabular}{|c|c|c|c|c|c|c|c|c|}
\hline \multirow[b]{2}{*}{ Variable } & \multicolumn{2}{|c|}{$\begin{array}{c}\text { Full Sample } \\
\mathrm{N}=523\end{array}$} & \multicolumn{2}{|c|}{$\begin{array}{l}\text { Disorder } \\
\mathrm{N}=172\end{array}$} & \multicolumn{2}{|c|}{$\begin{array}{l}\text { Greened } \\
\mathrm{N}=172\end{array}$} & \multicolumn{2}{|c|}{$\begin{array}{l}\text { CPTED } \\
\mathrm{N}=179\end{array}$} \\
\hline & $\bar{X}$ & SD & $\overline{\bar{X}}$ & SD & $\overline{\bar{X}}$ & SD & $\overline{\bar{X}}$ & SD \\
\hline Fear of Crime Index & 4.717 & 1.6433 & 5.6933 & 1.4509 & 4.4095 & 1.4964 & 4.0744 & 1.5225 \\
\hline
\end{tabular}


Table 6.

\begin{tabular}{|c|c|c|c|c|}
\hline & Template & Disorderly & $\begin{array}{l}\text { Traditional } \\
\text { Practices }\end{array}$ & CPTED \\
\hline Adjustments & $\begin{array}{l}\text { The following } \\
\text { features will be } \\
\text { removed: } \\
\text { - Telephone } \\
\text { pole and } \\
\text { telephone } \\
\text { lines } \\
\text { - Evergreen } \\
\text { - Wooden, brick } \\
\text { and metal } \\
\text { fences } \\
\text { - Cracks in the } \\
\text { street } \\
\text { pavement and } \\
\text { sidewalk } \\
\text { Evergreen } \\
\text { - Cars parked in } \\
\text { the street }\end{array}$ & $\begin{array}{l}\text { The following } \\
\text { features will be } \\
\text { added: } \\
\text { - Overgrown } \\
\text { grass, bushes } \\
\text { and trees } \\
\text { - A pile of tires } \\
\text { - Piles of } \\
\text { cement } \\
\text { - Trash bags } \\
\text { - Abandoned } \\
\text { car } \\
\text { - Miscellaneous } \\
\text { debris }\end{array}$ & $\begin{array}{l}\text { The following } \\
\text { features will be } \\
\text { added: } \\
\text { - Trees planted } \\
\text { in a systematic } \\
\text { fashion }\end{array}$ & $\begin{array}{l}\text { The following } \\
\text { features will be } \\
\text { added: } \\
\text { - Fencing } \\
\text { - Signage } \\
\text { - Artwork } \\
\text { - Flowers and } \\
\text { low-lying bushes } \\
\text { - Clearly defined } \\
\text { exit and entrance } \\
\text { - Clearly defined } \\
\text { - } \text { route } \\
\text { - Lighting }\end{array}$ \\
\hline
\end{tabular}

Table 7.

Lumpkin's Abbreviated Locus of Control Scale

\begin{tabular}{|l|l|}
\hline \multicolumn{1}{|c|}{ Internals } & \multicolumn{1}{c|}{ Externals } \\
\hline $\begin{array}{l}\text { When I make plans, I am almost certain that I } \\
\text { can make them work. }\end{array}$ & $\begin{array}{l}\text { Many of the unhappy things in people's lives are } \\
\text { partly due to bad luck. }\end{array}$ \\
$\begin{array}{l}\text { Getting people to do the right things depends } \\
\text { upon ability; luck has nothing to do with it. }\end{array}$ & $\begin{array}{l}\text { Getting a good job depends mainly on being in } \\
\text { the right place at the right time. } \\
\text { What happens to me is my own doing. }\end{array}$ \\
\hline
\end{tabular}


Table 8.

Individual-level Characteristics Descriptive Statistics

\begin{tabular}{lcccc}
\hline & Full Sample & Disorder & Greened & CPTED \\
& $\mathrm{N}=523$ & $\mathrm{~N}=172$ & $\mathrm{~N}=172$ & $\mathrm{~N}=179$ \\
\hline Variable & $\bar{X}$ & $\bar{X}$ & $\bar{X}$ & $\bar{X}$ \\
\hline Sex & 0.48 & 0.51 & 0.47 & 0.46 \\
Age & 19.63 & 19.66 & 19.74 & 19.51 \\
Federal Pell Grant & 0.26 & 0.19 & 0.30 & 0.28 \\
Direct Victimization & 0.25 & 0.19 & 0.24 & 0.31 \\
Indirect Victimization & 0.37 & 0.36 & 0.36 & 0.40 \\
Suburban & 0.75 & 0.78 & 0.72 & 0.75 \\
Rural & 0.14 & 0.13 & 0.15 & 0.15 \\
Urban & 0.11 & 0.09 & 0.13 & 0.11 \\
White & 0.64 & 0.66 & 0.63 & 0.63 \\
Black & 0.15 & 0.12 & 0.17 & 0.16 \\
Hispanic & 0.13 & 0.13 & 0.12 & 0.13 \\
Asian & 0.13 & 0.13 & 0.13 & 0.14 \\
Other Race & 0.07 & 0.09 & 0.06 & 0.07 \\
Internal & 0.48 & 0.46 & 0.47 & 0.51 \\
\hline
\end{tabular}


Table 9.

Assessment of Equivalence

\begin{tabular}{llll}
\hline Variable & Greened \& Disorder & CPTED \& Greened & CPTED \& Disorder \\
\hline Sex & -0.6472 & -0.136 & -0.7895 \\
Age & 0.3279 & -1.0833 & -0.6505 \\
Pell Grant & $2.3751^{*}$ & -0.3581 & $2.0426^{*}$ \\
Direct Victimization & 1.1752 & 1.4335 & $2.6046^{* *}$ \\
Indirect Victimization & 0.0000 & 0.6985 & 0.6985 \\
Suburban & -1.3644 & 0.7083 & -0.6715 \\
Rural & 0.4628 & -0.1558 & 0.3116 \\
Urban & 1.376 & -0.7957 & 0.5996 \\
White & -0.5646 & -0.0473 & -0.6173 \\
Black & 1.5298 & -0.3107 & 1.2358 \\
Hispanic & -0.3229 & 0.181 & -0.1451 \\
Asian & -0.1599 & 0.3234 & 0.162 \\
Other Race & -0.8159 & 0.1168 & -0.7089 \\
Internal & 0.1081 & 0.9152 & 1.0243 \\
\hline Note. The & & & \\
\hline
\end{tabular}

Note. The values presented in this table for all variables other than Age are z-statistics. The values presented for the variable Age are t-statistics.

$* \mathrm{p}<0.05, * * \mathrm{p}<0.05$

Table 10.

OLS Regression

\begin{tabular}{lll}
\hline Variable & $\beta$ Coefficient & Standard Error \\
\hline Greened & $-1.2933^{* *}$ & 0.1618 \\
CPTED & $-1.6164 A^{* *}$ & 0.1608 \\
Direct Victimization & -0.1369 & 0.1516735 \\
Pell Grant & 0.1507 & 0.1497 \\
\hline
\end{tabular}

$\mathrm{N}=523, * \mathrm{p}<0.05, * * \mathrm{p}<0.01$

$\mathrm{A}=$ This value is significantly different from the greened value 
Table 11.

\section{OLS Regression with No Controls}

\begin{tabular}{lll}
\hline Variable & $\beta$ Coefficient & Standard Error \\
\hline Greened & $-1.2838^{* *}$ & 0.1608 \\
CPTED & $-1.6190 * *$ & 0.1591 \\
\hline
\end{tabular}

$\mathrm{N}=523, * \mathrm{p}<0.05, * * \mathrm{p}<0.01$

$\mathrm{A}=$ This value is significantly different from the greened value 


\section{References}

Abdullah, A., Hedayati, M. M. \& Maghsoodi, T. M. J. (2013). Predicting the influence of CPTED on perceived neighbourhood cohesion: considering differences across age. Journal of Environmental Psychology, 36(3), 54-64.

Abdullah, A., Hedayati, M. M., Haron, S. H., Bahauddin, A. \& Maghsoodi, T. M. J. (2013). A cross-cultural validation of the territorial functioning construct in residential neighbourhoods: A multigroup invariance analysis. Review of European Studies, 5(5), 30-39.

Alper M., \& Chappell A.T. (2012). Untangling fear of crime: A Multi-theoretical Approach to examining the causes of crime-specific fear. Sociological Spectrum, 32(4), 346-363.

Andrews, M. \& Gatersleben, B. (2010). Variations in perceptions of danger, fear and preferences in a simulated natural environment. Journal of Environmental Psychology, 30, 473-481.

Angel, Schlomo. (1968). Discouraging crime through city planning. (Paper No. 75). Berkeley, CA: Center for Planning and Development Research, University of California at Berkeley.

Appleton, J. (1975). The Experience of Landscape. London: Wiley.

Armitage, R. (2002). To cctv or not to cctv? a review of current research into the effectiveness of cctv systems in reducing crime. London: Nacro, Crime and Social Policy Section.

Arnold, H. (1991). Fear of crime and its relationship to directly and indirectly experienced victimization: A binational comparison of models. In K. Sessar and H. J. Kerner,(Eds.), Developments in crime and crime control research: German studies on victims, offenders, and the public, Springer-Verlag; New York.

Atlas, R (1986). Crime prevention through building codes. Journal of Security Administration, 9(2), 3-12.

Austin, D. M., \& Sanders, C. (2007). Graffiti and perceptions of safety: A pilot study using photographs and survey data. Journal of Criminal Justice and Popular Culture, 14(4), 292-316.

Baltimore Greenspace. (2013). Retrieved from http://baltimoregreenspace.org/

Baumer, T.L. (1985). Testing a general model of fear of crime: Data from a national sample. Journal of Research in Crime and Delinquency, 22(3), 239-255. 
Beavers, Amy S., Lounsbury, John W., Richards, Jennifer K., Huck, Schuyler W., Skolits, Gary J. \& Esquivel, Shelley L. (2013). Practical considerations for using exploratory factor analysis in educational research. Practical Assessment, Research \& Evaluation, 18(6).

Bell, W. (1991). The role of urban design in crime prevention. Australian Planner, 29(4) 206-210.

Bell, W. (1992). Crime prevention: A planning and urban design approach (Research report). Adelaide: Crime Prevention Unit, SA Attorney General's Department.

Bennett, R. R., \& Flavin, J. M. (1994). Determinants of fear of crime: The effect of cultural setting. Justice Quarterly, 11, 357-381.

Bernstein, I. H., \& Teng, G. (1989). Factoring items and factoring scales are different: Spurious evidence for multidimensionality due to item categorization.

Psychological Bulletin, 105(3), 467-477.

Bickman, L., Maltz, M.D. \& Lavrakas, P.J. (1977). The evaluation of Crime prevention through environmental design programs. USA: Westinghouse Electric Corporation.

Bishop, I. D. \& Rohrmann, B. (2003). Subjective responses to simulated and real environments: A comparison. Landscape and Urban Planning, 65(4), 261-277.

Blakely, E. J. \& Snyder, M. G. (1997). Fortress America. Washington, DC: Brookings Institution.

Bowman, A.O. \& Pagano, M.A. (2000). Vacant land in cities: an urban resource. The Bookings Institution: Center of Urban on Urban and Metropolitan Policy, 1-9.

Braga, A. A. (2008). Problem-oriented policing and crime prevention. Second edition. Boulder, CO: Lynne Rienner Publishers.

Branas, C. C., Cheney, R. A., MacDonald, J. M., Tam, V. W., Jackson, T. D., \& Ten, H. T. R. (January 01, 2011). A difference-in-differences analysis of health, safety, and greening vacant urban space. American Journal of Epidemiology, 174(11), 1296-306.

Brantingham, P. J., \& Brantingham, P. L. (1981). Environmental criminology. Beverly Hills, CA: Sage Publications.

Brower, S. (1980). Territory in urban settings. In A.A. Rapoport, \& J. F. Wohlwill (Eds.), Culture and environment. human behavior and environment, 4. New York: Plenum. 
Brower, S., Dockett, K. \& Taylor, R. B. (1983). Residents' perceptions of territorial features and perceived local threat. Environment and Behavior, 15(4), 419-437.

Brown, B. B., \& Werner, C. M. (1985). Social cohesiveness, territoriality and holiday decorations: the influence of cul-de-sacs. Environment and Behavior, 17, 539565 .

Bugaighis, M. \& Walter R. (1983). Alternative measures of perceived locus of control. Psychological Reports, 52, 819-823.

Bureau of Justice Assistance, U.S. Department of Justice. (2015). Center for Program Evaluation and Performance Measurement. Retrieved from https://www.bja.gov/evaluation/program-crime-prevention/cpted1.htm.

Bureau of Justice Statistics. (2013). National crime victimization survey. Retrieved from http://www.bjs.gov/index.cfm?ty=dcdetail\&iid=245

Burkholder, S. (2012). The new ecology of vacancy: rethinking land use in shrinking cities. Sustainability, 4(6), 1154-1172.

Caliendo, M., Cobb-Clark, D. \& Uhlendorff, (2010) A. Locus of control and job strategies. (Discussion Paper No. 4750).

Casteel, C. \& Peek-Asa, C. (2000). Effectiveness of crime prevention through environmental design (CPTED) in reducing robberies. American Journal of Preventive Medicine, 18(4), 99-115.

Challinger, Dennis. (1997). Refund fraud in retail stores. In R. V. Clarke (Ed.), Situational crime prevention: Successful case studies (Second Edition). Albany, NY: Harrow and Heston.

Cinar, E. A., \& Cubukcu, E. (2012). The influence of micro scale environmental characteristics on crime and fear. Procedia - Social and BehavioralvSciences, 35(2), 83-88.

Clarke, R. V. (1995). Situational crime prevention. In M. Tonry \& D. Farrington (Eds.), Crime and justice: building a safer society (pp. 91-150). Chicago: Chicago University Press.

Clarke, R. V. \& Derek B. C. (1985). Modeling offenders' decisions: a framework for research and policy. In M. Tonry and N. Morris (Eds.), Crime and Justice: an annual review of research (pp. 147-185). Chicago: University of Chicago Press.

Clarke, R.V. \& Mayhew P. (Eds.). (1980). Designing out crime. London: Home Office Research and Planning Unit (HMSO). 
Clifton W. (1987). Convenience store robberies in Gainesville, Florida: An intervention strategy by the Gainesville Police Department. Gainesville, FL: Gainesville Police Department.

Cohen, J. (1970). Approximate power and sample size determination for common onesample and two sample hypothesis tests. Educational and Psychological Measurement, 30, 811-831.

Cohen, J. (1988). Statistical power analysis for the behavioral sciences (2nd ed.). Hillsdale, NJ: Lawrence Erlbaum.

Costello, Anna B. \& Jason Osborne (2005). Best practices in exploratory factor analysis: four recommendations for getting the most from your analysis. Practical Assessment Research \& Evaluation, 10(7).

Covington, J., \& Taylor, R. B. (1991). Fear of crime in urban residential neighborhoods: Implications of between- and within-neighborhood sources for current models. Sociological Quarterly, 32(2), 231-249.

Cozens, P., Hillier, D. \& Prescott, G. (2001). Crime and the design of residential property exploring the perceptions of planning professionals, burglars and other users: Part 2. Property Management, 19(4), 222-248.

Cozens, P., Neale, R., \& Hillier, D. (2003). Managing crime and the fear of crime at railway stations: A case study in South Wales (UK). International Journal of Transport Management, 1(3), 121-132.

Cozens, P., Neal, R., Hillier, D. \& Whitaker, J. (2004). Tackling crime and fear of crime while waiting at Britain's railway stations. Journal of Public Transportation, 7(3), 23-42.

Cozens, P., Neal, R., Whitaker, J. \& Hillier, D. (2003). Investigating personal safety at railway stations using "virtual reality" technology. Facilities, 21(7/8), 188-194.

Cozens, P., Saville, G. \& Hillier D. (2005). Crime prevention through environmental design (CPTED): a review and modern bibliography. Property Management, 23(5), 328-356.

Crowe, T. D., \& National Crime Prevention Institute (University of Louisville). (1991).Crime prevention through environmental design: applications of architectural design and space management concepts. Boston: ButterworthHeinemann.

Data Driven Detroit. (2015). Motor City Mapping. Retrieved from http://datadrivendetroit.org/data-mapping/ 
Day, K. (1994). Conceptualizing women's fear of sexual assault on campus: A review of causes and recommendations for change. Environment and Behavior, 26(6), 742765.

Doran, B. J. \& Burgess, M. B. (2012). Putting fear of crime on the map: investigating perceptions of crime using geographic information systems. New York, NY: Springer.

Doran, B. J. \& Lees, B. G. (2005). Investigating the spatiotemporal links between disorder, crime, and the fear of crime. The Professional Geographer, 57(1), 1-12.

Dubow, F., McCabe F. \& Kaplan, G. (1979). Reactions to crime: a critical review of the literature. Washington, DC: U.S.

Erickson, R.J. (1998). Convenience store security at the millennium. Alexandria, VA: National Association of Convenience Stores.

Fabrigar, L. R., Wegener, D. T., MacCallum, R. C., \& Strahan, E. J. (1999). Evaluating the use of exploratory factor analysis in psychological research. Psychological Methods, 4(3), 272-299.

Farrall, S., Bannister, J., Ditton, J., \& Gilchrist, E. (1997). Questioning the measurement of the 'fear of crime': Findings from a major methodological study. British Journal of Criminology, 37(4), 658-679.

Farrington, D.P. \& Welsh, B. (2002). Improved street lighting and crime prevention. Justice Quarterly, 19(2), 313-342.

Federal Bureau of Investigation. (2014). Uniform Crime Report. Retrieved from http://www.fbi.gov/about-us/cjis/ucr/crime-in-the-u.s/2011/crime-in-the-u.s.2011/about-cius.

Fennelly, L., \& Crowe, T. (2013). Crime Prevention Through Environmental Design. Burlington: Elsevier Science.

Ferraro, K.F. (1995) Fear of crime: Interpreting victimization risk. Albany: State University of New York Press.

Ferraro, K. F. (1996). Women's fear of victimization: shadow of sexual assault?. Social Forces, 75(2), 667-690.

Ferraro, K. F. \& LaGrange, R. (1987). The Measurement of Fear of Crime. Sociological Inquiry, 57(1), 70-97. 
Figlio, R. \& Aurand, S. (1991). Closed circuit interactive television and crime. In, Convenience store security: complete text reports with summary. Alexandria, VA: National Association of Convenience Stores.

Fisher, B.S. \& Nasar, J.L. (1992). Fear of crime in relation to three exterior site features: prospect, refuge, and escape. Environment and Behavior, 24(1), 35-65.

Fisher, B.S., Sloan, J. J. \& Wilkins, D. L. (1995). Fear of crime and perceived risk of victimization in an urban university setting. In B. S. Fisher \& J. J. Sloan (Eds.), Campus crime: Legal, social and policy perspectives. Springfield, IL: Charles Thomas

Flynn, J., Slovic, P. and Mertz, C.K. (1994). Gender, race, and perception of environmental health risks, Risk Analysis, 14(6), 1101-1108.

Fox, K., Nobles, M. \& Piquero, A. (2009). Gender, crime victimization and fear of crime. Security Journal, 22(1), 24-39.

Fowler, F. J. (2014). Survey research methods (5th ed.). Newbury Park: Sage Publications.

Gabriel, U., \& Greve, W. (2003). The psychology of fear of crime: conceptual and methodological perspectives. The British Journal of Criminology, 43(3), 600-614.

Garofalo, J. (1979). Victimization and the Fear of Crime. Journal of Research in Crime and Delinquency, 16(1), 80-97.

Glazer, N. (1979). On subway graffiti in New York. Public Interest, 54, 3-11.

Gibson, C., Zhao, J., Lovrich, N., \& Gaffney, M. (2002). Social integration, individual perceptions of collective efficacy, and fear of crime in three cities. Justice Quarterly, 19 (3), 537-564.

Gomme, I.M. (1986). Fear of crime amongst Canadians: A multi-variate analysis. Journal of Criminal Justice, 14, 249-258.

Green, G. (2002). Fear of crime and health in residential tower blocks: A case study in Liverpool, UK. The European Journal of Public Health, 12(1), 10-15.

Green, G., Gilbertson, J. M., \& Grimsley, M. F. (2002). Fear of crime and health in residential tower blocks: a case study in Liverpool, UK. European Journal of Public Health, 12(1), 10-5.

Greenbaum, P. \& Greenbaum, S. (1981). Territorial personalization. Environment and Behavior, 13(5), 574-589. 
The Greening of Detroit. (2014). Retrieved from http://www.greeningofdetroit.com/.

Grice, J. W. (2001). Computing and evaluating factor scores. Psychological Methods, $6(4), 430-450$.

Grice, J.W. (2007). Factor scores. In N. Salkind \& K. Rasmussen (Eds.), Encyclopedia of measurement and statistics. Thousand Oaks, CA: Sage Publications.

Hale, C. (1996). Fear of crime: A review of the literature. International Review of Victimology, 4, 79-150.

Hanyu, K. (1993). The affective meaning of Tokyo: Verbal and nonverbal approaches. Journal of Environmental Psychology, 13, 161-172.

Harcourt, B. E. (2001). Illusion of order: The false promise of broken windows policing. Cambridge, MA: Harvard University Press.

Heckert M. \& Mennis J. (2012). The economic impact of greening urban vacant land: A spatial difference-in-differences analysis. Environment and Planning, 44(12), $3010-3027$

Hedayati, M.M., Abdullah, A., Razak, N. A. \& Maghsoodi, T. M. J. (2012a). The influence of crime prevention through environmental design on victimisation and fear of crime. Journal of Environmental Psychology, 3(2), 79-88.

Hedayati, M.M., Abdullah, A., Razak, N. A. \& Maghsoodi, T. M. J. (2012b). Validating crime prevention through environmental design construct through checklist using structural equation modelling. International Journal of Law, Crime and Justice, 40(2), 82-99.

Heckert, M. \& Mennis, J. (2012). The economic impact of greening urban vacant land: a spatial difference-in-differences approach. Environment and Planning, 44(12), 3010-3027.

Heller, D.E. (2007).Pell Grant recipients in selective colleges and universities. The Century Foundation.

Hendricks, D., Landsittel, H., Amandus, J. \& Malcan, J. Bell. (1999). A matched casecontrol study of convenience store robbery risk factors. Journal of Occupational Environmental Medicine, 41(11), 995-1004

Herzog, T. \& Bryce, A. (2007). Mystery and preference in within-forest settings. Environment and Behavior, 39(6), 779-796. 
Herzog, T. R. \& Flynn-Smith, J. A. (2001). Preference and perceived danger as a function of the perceived curvature, length, and width of urban alleys. Environment and Behavior, 33(5), 653-666.

Hindelang, M. J., Gottfredson, M. R. \& Garofalo, J. (1978). Victims of personal crime: An empirical foundation for a theory of personal victimization. Cambridge, MA: Ballinger Publishing Company.

Hinkle, J. C. (2005). The impact of disorder on fear of crime: A test of the first link of broken windows. College Park, MD: University of Maryland.

Hinkle, J. C. \& Weisburd, D. (2008). The irony of broken windows policing: A micro-place study of the relationship between disorder, focused police crackdowns and fear of crime. Journal of Criminal Justice, 36(6), 503-512.

Houtkamp, J. M., \& Junger, M. L. A. (2010). Affective qualities of an urban environment on a desktop computer. In E. Banissi (Ed.), Proceedings of the 14th International Conference information Visualisation (IV 2010) (pp. 597-603). Los Alamitos, CA, USA: IEEE Computer Society.

Hunter, R.D. (1990). Convenience store robbery in Tallahassee: a reassessment. Journal of Security Administration, 13(1-2), 3-18.

Jackson, J. (2004). Experience and expression social and cultural significance in the fear of crime. The British Journal of Criminology, 44(6), 946-966.

Jackson, J. (2006). Introducing fear of crime to risk research. Risk Analysis, 26(1), 253264.

Jackson, J. (2011). Revisiting risk sensitivity in the fear of crime. Journal of Research in Crime and Delinquency, 48(4), 513-537.

Jacobs, J. (1961). The Death and Life of Great American Cities. New York: Random House.

Jans, M. \& Roman, A. M. (2007). National response rates for surveys of college students: Institutional, regional, \& design factors. American Association for Public Opinion Research Annual Conference, Anaheim. Published in the American Statistical Association Proceedings.

Jeffery, C. R. (1971). Crime Prevention Through Environmental Design. Beverly Hills, CA:Sage Publications.

Jeffery, C. R. (1977). Crime Prevention Through Environmental Design. London, UK: Sage Publications.

Jorgensen, L. J., Ellis, G. D., \& Ruddell, E. (2013). Fear perceptions in public parks: 
Interactions of environmental concealment, the presence of people recreating, and gender. Environment and Behavior, 45(7), 803-820.

Kaplan, S. (1979). Perception and landscape: conceptions and misconceptions. In Elsner, G. H. \& and Smardon, R.C. (Eds.), Proceedings of our national landscape: a conference on applied techniques for analysis and management of the visual resource, Berkeley, CA: U.S. Department of Agriculture.

Keane, Carl. (1995). Victimization and fear: Assessing the role of the offender and the offence. Canadian Journal of Criminology, 37, 431-455.

Kelley, K. \& Maxwell, S. E. (2003). Sample size for multiple regression: Obtaining regression coefficients that are accurate, not simply significant. Psychological Methods, 8, 305-321.

Kushmuk, J. \& Whittermore, S. (1981). A reevaluation of the CPTED program in Portland. Washington DC: NIJ.

La Vigne, N.G. (1997). Visibility and vigilance: Metro's situational approach to preventing subway crime. Washington, DC: U.S. Dept. of Justice, Office of Justice Programs, National Institute of Justice.

Lab, S. P. (2014). Crime prevention: Approaches, practices, and evaluations. Boston, MA: Anderson Publishing/Elsevier.

LaGrange, R.L., Ferraro, K.F. \& Supancic, M. (1992). Perceived risk and fear of crime: role of social and physical incivilities. Journal of Research in Crime and Delinquency, 29(3), 311-334.

Lamb, R.C., Hunter, R.D. \& McLain, D.J. (1993). Fear reduction in the Charlotte Housing Authority. In Zahm, D. \& P. Cromwell (Eds.), Proceedings of the international seminar on the environmental criminology and crime analysis. Coral Gables, FL: Florida Criminal Justice Executive Institute.

Liska, A. E., Sanchirico, A. \& Reed, M. D. (1988). Fear of crime and constrained behavior specifying and estimating a reciprocal effects model. Social Forces, 66(3), 827-837.

Lumpkin, J. R (1985). Validity of a brief locus of control scale for survey research. Psychological Reports, 57, 655-659.

Markowitz, F., Bellair, P., Liska, A. \& Liu, J. (2001). Extending social disorganization theory: Modeling the relationships between cohesion, disorder, and fear. Criminology, 39(2), 293-319. 
Maroof, D. (2012). Statistical methods in neuropsychology: Common procedures made comprehensible. New York: Springer.

Maxwell, S. E. (2000). Sample size and multiple regression. Psychological Methods, 5, 434-458.

Mayhew, P., Clarke, R.V. \& Elliott, D. (1989). Motorcycle theft, helmet legislation and displacement. The Howard Journal of Criminal Justice, 28(1), 1-8.

Mayhew, P., Clarke, R.V., Sturman, A. \& Hough, J.M. (1976). Crime as opportunity. Home office research study. London: H.M. Stationery Office.

McGarrell, E., Gizcomazzi, A. L. \& Thurman, Q. C. Reducing disorder, fear, and crime in public housing: A case study of place-specific crime prevention. Justice Research and Policy. 1(2), 61-87.

Minnery, J. R. \& Lim, B. (2005). Measuring crime prevention through environmental design. Journal of Architectural and Planning Research, 22(4), 330-341.

Moffat, R. (1983). Crime prevention through environmental design - a management perspective. Canadian Journal of Criminology, 25(4), 19-31.

Morrall, P., Marshall, P., Pattison, S. \& Macdonald, G. (2010). Crime and health: a preliminary study into the effects of crime on the mental health of UK university students. Journal of Psychiatric and Mental Health Nursing, 17(9), 821-828.

Morrow, E. N., \& Hutton, S. A. (2000). The Chicago alley lighting project: final evaluation report. Chicago, IL: Illinois Criminal Justice Information Authority.

Nasar, J.L. \& Fisher, B.S. (1992). Design for vulnerability: cues and reactions to fear of crime. Sociology and Social Research, 76(2), 48-58.

Nasar, J.L. \& Jones, K. (1997). Landscapes of fear and stress. Environment and Behavior, 29(3), 291-323.

National Opinion Research Center. (2012). General Social Survey. Retrieved from http://www.norc.org/Research/Projects/Pages/general-social-survey.aspx.

Newman, O. (1972). Defensible Space: Crime Prevention through Urban Design. New York: Macmillan.

Office for International Statistics. (2014). Crime survey. Retrieved from http://www.crimesurvey.co.uk/previous-research.html.

Olsson, U. (1979). Maximum likelihood estimation of the polychoric correlation coefficient. Psychometrika, 44(4), 443-460. 
Pain, R. (2000). Place, social relations and the fear of crime: a review. Progress in Human Geography, 24(3), 365-387.

Painter, K. \& Farrington, D.P. (1997). The crime reducing effect of improved street lighting: The dudley project. In R.V. Clarke (Ed.), Situational crime prevention: successful case studies, 2nd edition, New York, NY: Harrow and Heston.

Palmer, J. F. \& Hoffman, R. E. (2001). Rating reliability and representation validity in scenic landscape assessments. Landscape and Urban Planning, 54(1-4), 149-161.

Park, A.J. (2008). Modeling the role of fear of crime in pedestrian navigation. Burnaby, BC: Simon Fraser University.

Park, A. J., Clare, J., Spicer, V., Brantingham, P. L., Calvert, T. \& Jenion, G. (2012). Examining context-specific perceptions of risk: Exploring the utility of "humanin-the-loop" simulation models for criminology. Journal of Experimental Criminology, 8(1), 29-47.

Park, A. J., Hwang, E., Spicer, V., Cheng, C., Brantingham, P. L. \& Sixsmith, A. (2011). Testing elderly people's fear of crime using a virtual environment. In Proceedings of the 2011 European Conference on Intelligence and Security Informatics (EISIC) (pp. 63-69). IEEE.

Parker, K. \& Ray, M.C. (1990). Fear of crime: An assessment of related factors. Sociological Spectrum, 10(1), 29-40

Parnaby, P. F. (2006). Crime prevention through environmental design: discourses of risk, social control, and a neo-liberal context. Canadian Journal of Criminology and Criminal Justice, 48(1), 1-30.

The Pennsylvania Horticultural Society. (2014). Retrieved from http://phsonline.org/

Perkins, D.D. \& Taylor, R. (1996). Ecological assessments of community disorder: Their relationship to fear of crime and theoretical implications. American Journal of Community Psychology, 24(1), 63-107.

Perkins, D.D., Meeks, J.W. \& Taylor, R.B. (1992). The physical environment of street blocks and resident perceptions of crime and disorder: Implications for theory and measurement. Journal of Environmental Psychology, 12, 21-34.

Perkins, D.D., Wandersman, A., Rich, R.C., \& Taylor, R.B. (1993). The physical environment of street crime: defensible space, territoriality and incivilities. Journal of Environmental Psychology, 13, 29-49.

Petherick, N. (2000). Environmental design and fear: The prospect-refuge model and the 
university college of the cariboo campus. Western Geography, 10/11, 88-112.

Pett, M., Lackey, N. \& Sullivan, J. (2003). Making sense of factor analysis. Thousand Oaks: Sage Publications, Inc.

Pitner, R., Yu, M., \& Brown, E. (2012). Making neighborhoods safer: Examining predictors of residents' concerns about neighborhood safety. Journal of Environmental Psychology, 32 (1), 43-49.

Pollack, L. M. \& Patterson, A. H. (1980). Territoriality and fear of crime in elderly and nonelderly homeowners. The Journal of Social Psychology, 111, 119-129.

Porter, R. \& Fabrigar, L. (2007). Factor Analysis. In N. Salkind \& K. Rasmussen (Eds.), Encyclopedia of measurement and statistics (pp. 342-246). Thousand Oaks, CA: SAGE Publications.

Poyner, B. and Webb, B. (1987) Successful crime prevention case studies. Document No. 2T 563. London: Tavistock Institute of Human Relations.

Prociuk, T. J., Breen, L. J. \& Lussier, R. J. (1976). Hopelessness, internal-external locus of control, and depression. Journal of Clinical Psychology, 32(2), 299-300.

Riechard, D. E. \& Peterson, S. J. (1998). Perception of environmental risk related to gender, community socioeconomic setting, age, and locus of control. Journal of Environmental Education, 30(1), 11-19.

Ross, C. E. \& Mirowsky, J. (2001). Health and illness - neighborhood disadvantage, disorder, and health. Journal of Health \& Social Behavior, 42(3), 258-276.

Rossi, J. S. (1990). Statistical power of psychological research: What have we gained in 20 years? Journal of Consulting and Clinical Psychology, 58, 646-656.

Rotter, J. B. (1966). Generalized expectancies for internal versus external control of reinforcement. Psychological Monographs, 80(1), 1-28.

Rountree, P. W. \& Land, K. C. (1996). Perceived risk versus fear of crime: Empirical evidence of conceptually distinct reactions in survey data. Social Forces, 74, 1353-1376.

Ruscio, J., \& Roche, B. (2012). Determining the number of factors to retain in an exploratory factor analysis using comparison data of known factorial structure. Psychological Assessment, 24(2), 282-92.

Rusticus, Shayna A. \& Chris Y. Lovato (2011). Applying Tests of Equivalence for Multiple Group Comparisons: Demonstration of the Confidence Interval Approach. Practical Assessment, Research \& Evaluation, 16(7). 
Sakip, S. R. M., Johari, N. \& Salleh, M. N. M. (2012). The Relationship between crime prevention through environmental design and fear of crime. Procedia-Social and Behavioral Sciences, 68(4), 628-636.

Sampson, R. \& Raudenbush, S. (2004). Seeing disorder: neighborhood stigma and the social construction of "broken windows". Social Psychology Quarterly, 67(4), 319-342.

Schmuckler, M.A. (2001). What is ecological validity? A dimensional analysis. International Society on Infant Studies, 2(4), 419-436.

Schneider, R.\& Kitchen, T. (2002). Planning For Crime Prevention: A Transatlantic Perspective, Routledge, London.

Schneider, R. H. \& Kitchen, T. (2007). Crime prevention in the built environment. New York, NY: Routledge, Taylor \& Francis Group.

Schwebel, D. C., Gaines, J. \& Severson, J. (2008). Validation of virtual reality as a tool to understand and prevent child pedestrian injury. Accident Analysis \& Prevention, 40(4), 1394-1400.

Shadish, W. R., Cook, T. D. \& Campbell, D. T. (2002). Experimental and quasiexperimental designs for generalized causal inference. Boston, MA: Houghton Mifflin.

Silver, E. \& Miller, L. (2004). Sources of informal social control in Chicago. Criminology, 42 (3), 551-584.

Skinner, B. F. (1938). The Behavior of Organisms: An Experimental Analysis. New York, London: D. Appleton-Century Company, Incorporated.

Skogan, W. (1986). Fear of Crime and Neighborhood Change. Crime and Justice, 8, 203229.

Skogan, W. (1987). The impact of victimization on fear of crime. Crime and Delinquency, 33, 135-154.

Skogan, W. (1990). Disorder and decline: Crime and the spiral of decay in American neighborhoods. New York: Free Press.

Skogan, W. \& Maxfield, M. G. (1981). Coping with crime: Individual and neighborhood reactions. Beverly Hills: Sage Publications.

Sloan, J.J., Fisher, B.S. \& Wilkins, D.L. (1996). Reducing perceived risk and fear of victimization on campus: a panel study of faculty members, staff, and 
students. Journal of Contemporary Criminal Justice, 12(1), 81-107.

Slovic, P., \& International Institute for Environment and Development. (2010). The feeling of risk: New perspectives on risk perception. London: Earthscan.

Smith, G. \& Lab, S. (1991). Urban and rural attitudes toward participating in an auxiliary policing crime prevention program. Criminal Justice and Behavior, 18(2), 202216.

Spelman, W. (1993). Abandoned houses: magnets for crime? Journal of Criminal Justice, $21,481-495$.

Stamps, A.E. (1990). Use of photographs to stimulate environments: A meta-analysis. Perceptual and Motor Skills, 71, 907-913.

Stamps, A.E. (2010). Use of static and dynamic media to simulate environments: A metaanalysis. Perceptual and Motor Skills, 111(2), 355-364.

Stamps, A.E. (2005). Visual permeability, locomotive permeability, safety, and enclosure. Environment and Behavior, 37(5), 587-619.

Stamps, A. E., \& Smith, S. (2002). Environmental enclosure in urban settings. Environment and Behavior, 34(6), 781-794.

Suhr, D. (2006). Exploratory or Confirmatory Factor Analysis. SAS Users Group International Conference (pp. 1 - 17). Cary: SAS Institute, Inc.

Sutton, A., Cherney, A., \& White, R. (2008). Crime prevention: principles, perspectives and practices. Cambridge, UK: Cambridge University Press.

Taylor, R. B. (1996). Neighborhood responses to disorder and local attachments: The systemic model of attachment, social disorganization, and neighborhood use value. Sociological Forum, 11(1), 41.

Taylor, R. B. \& Harrell, A. (1996) Physical environment and crime. Washington: National Institute of Justice.

Taylor, R. B., Shumaker, S. \& Gottfredson, S. (1985). Neighborhood-level links between physical features and local sentiments. Journal of Architectural Planning and Research, 2, 261-275.

Toet, A., \& van Schaik, M.G. (2012). Effects of signals of disorder on fear of crime in r real and virtual environments. Journal of Environmental Psychology, 32(3), 260276.

Toseland, R.W. (2002). Fear of crime: Who is most vulnerable?. Journal of Criminal 
Justice,10(3), 199-209.

Troy, A., Morgan, G. J. \& O’Neil-Dunne, J. (2012). The relationship between tree canopy and crime rates across an urban-rural gradient in the greater Baltimore region. Landscape and Urban Planning, 106 (3), 262-270.

Uebersax, J. (2015). Introduction to the tetrachoric and polychoric correlation coefficients. Retrieved from http://john-uebersax.com/stat/tetra.htm

United States Environmental Protection Agency. (2013). What are vacant lots? Retrieved from http://www.epa.gov/region1/eco/uep/vacantlots.html

Urban Green Council. (2014). Retrieved from http://urbangreencouncil.org/ van Hagen, M. (2011). Waiting experience at train stations. Delft, Netherlands: Eburon.

Vanderveen, G. (2006). Interpreting fear, crime, risk, and unsafety: conceptualisation and measurement. Den Haag: Boom Juridische Uitgevers.

Wallis, A. \& Ford, D. (1981). Crime prevention through environmental design: An operational handbook. Washington, D.C: U.S. Department of Justice, National Institute of Justice.

Wang, K. \& Taylor, R. B. (2006). Simulated walks through dangerous alleys: Impacts of features and progress on fear. Journal of Environmental Psychology, 26, 269283.

Ward, C. (Ed.). (1973). Vandalism. London: Architectural Press.

Warr, M. (1985). Fear of rape among urban women. Social Problems, 32(3), 238-250.

Warr, M. (1987). Fear of victimisation and sensitivity to risk. Journal of Quantitative Criminology, 3(1), 29-46.

Warr, M. (1990). Dangerous situations: social context and fear of victimization. Social Forces, 68(3), 891-907.

Warr, M. (1994). Fear of victimization: Why are women and the elderly more afraid?. Social Science Quarterly, 65(3), 681-702.

Warr, M., \& Stafford, M. (1983). Fear of victimization: A look at the proximate causes. Social Forces, 61 (4), 1033-1043.

Welsh, B.C. \& Farrington, D. P. (2004). Surveillance for crime prevention in public space: results and policy choices in Britain and America. Criminology \& Public Policy, 3(3), 497-526. 
Wikström, P. (1990). Delinquency and the urban structure. In P. Wikström (Ed.), Crime and measures against crime in the city, Stockholm, National Council for Crime Prevention.

Will, J.A. (1995). Crime, neighborhood perceptions, and the underclass the relationship between fear of crime and class position. Journal of Criminal Justice, 23(2), 163176.

Will, J.A. \& McGrath, J.H. (1995). Crime, neighborhood perceptions, and the underclass: The relationship between fear of crime and class position. Journal of Criminal Justice, 23(2), 163-176.

Wilson, J.Q. \& Kelling, G.L. (1982). Broken windows: the police and neighborhood safety. Atlantic Monthly, 249(3), 29-38.

Wilcox, R. P., \& Land, K. C. (1996). Burglary victimization, perceptions of crime risk, and routine activities: a multilevel analysis across Seattle neighborhoods and census tracts. The Journal of Research in Crime and Delinquency, 33(2), 147180.

Wood, E. (1961). Housing Design: A Social Theory. New York, NY: Citizens' Housing and Planning Counsel of New York. 